\title{
An intercomparison study of analytical methods used for quantification of levoglucosan in ambient aerosol filter samples
}

\author{
K. E. Yttri ${ }^{1}$, J. Schnelle-Kreis ${ }^{2}$, W. Maenhaut ${ }^{3,6}$, G. Abbaszade ${ }^{2}$, C. Alves $^{4}$, A. Bjerke ${ }^{1}$, N. Bonnier ${ }^{14}$, R. Bossi ${ }^{5}$, \\ M. Claeys ${ }^{6}$, C. Dye ${ }^{1}$, M. Evtyugina ${ }^{4}$, D. García-Gacio ${ }^{7}$, R. Hillamo ${ }^{8}$, A. Hoffer ${ }^{9}$, M. Hyder ${ }^{10,15}$, Y. Iinuma ${ }^{11}$, \\ J.-L. Jaffrezo ${ }^{12}$, A. Kasper-Giebl ${ }^{13}$, G. Kiss ${ }^{9}$, P. L. López-Mahia ${ }^{7}$, C. Pio ${ }^{4}$, C. Piot ${ }^{12,16}$, C. Ramirez-Santa-Cruz ${ }^{13}$,

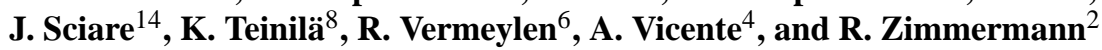 \\ ${ }^{1}$ NILU - Norwegian Institute for Air Research, P.O. Box 100, 2027 Kjeller, Norway \\ ${ }^{2}$ Helmholtz Zentrum München, Cooperation group Comprehensive Molecular Analytics, 85764 Neuherberg, Germany \\ ${ }^{3}$ Department of Analytical Chemistry, Ghent University, 9000 Gent, Belgium \\ ${ }^{4}$ Centre for Environmental and Marine Studies, Department of Environment, University of Aveiro, 3810-193 Aveiro, Portugal \\ ${ }^{5}$ Department of Environmental Science, Aarhus University, Frederiksborgvej 399, 4000 Roskilde, Denmark \\ ${ }^{6}$ Department of Pharmaceutical Sciences, University of Antwerp, Campus Drie Eiken, 2610 Antwerp, Belgium \\ ${ }^{7}$ Group of Analytical Chemistry (QANAP), Institute of Environment (IUMA), Department of Analytical Chemistry, \\ Faculty of Sciences, University of A Coruña, Campus de A Coruña, 15071 A Coruña, Spain \\ ${ }^{8}$ Finnish Meteorological Institute, Atmospheric Composition Research, Aerosol Research, Erik Palménin Aukio 1, 00560, \\ Helsinki, Finland \\ ${ }^{9}$ MTA-PE Air Chemistry Research Group, P.O. Box 158, 8201 Veszprém, Hungary \\ ${ }^{10}$ Center for Analysis and Synthesis, Department of Chemistry, Lund University, Sweden \\ ${ }^{11}$ Leibniz-Institut für Troposphärenforschung, Permoserstr. 15, 04138 Leipzig, Germany \\ ${ }^{12}$ Univ. Grenoble Alpes, LGGE, 38000 Grenoble, France, CNRS, LGGE, 38000 Grenoble, France \\ ${ }^{13}$ Institute of Chemical Technologies and Analytics, Vienna University of Technology, Getreidemarkt 9/164, \\ 1060 Vienna, Austria \\ ${ }^{14}$ Laboratoire des Sciences du Climat et de l'Environnement, CEA-CNRS-UVSQ, 91190 Gif-sur-Yvette, France \\ ${ }^{15}$ Pakistan Space and Upper Atmosphere research commission (SUPARCO), Lahore, Pakistan \\ ${ }^{16}$ Université de Savoie, LCME, 73376 Le Bourget du lac, France
}

Correspondence to: K. E. Yttri (key@nilu.no)

Received: 16 June 2014 - Published in Atmos. Meas. Tech. Discuss.: 23 July 2014

Revised: 4 December 2014 - Accepted: 4 December 2014 - Published: 9 January 2015

\begin{abstract}
The monosaccharide anhydrides (MAs) levoglucosan, galactosan and mannosan are products of incomplete combustion and pyrolysis of cellulose and hemicelluloses, and are found to be major constituents of biomass burning (BB) aerosol particles. Hence, ambient aerosol particle concentrations of levoglucosan are commonly used to study the influence of residential wood burning, agricultural waste burning and wildfire emissions on ambient air quality. A European-wide intercomparison on the analysis of the three monosaccharide anhydrides was conducted based on ambient aerosol quartz fiber filter samples collected at a Norwegian urban background site during winter. Thus, the sam-
\end{abstract}

ples' content of MAs is representative for BB particles originating from residential wood burning. The purpose of the intercomparison was to examine the comparability of the great diversity of analytical methods used for analysis of levoglucosan, mannosan and galactosan in ambient aerosol filter samples. Thirteen laboratories participated, of which three applied high-performance anion-exchange chromatography (HPAEC), four used high-performance liquid chromatography (HPLC) or ultra-performance liquid chromatography (UPLC) and six resorted to gas chromatography (GC). The analytical methods used were of such diversity that they should be considered as thirteen different analytical meth- 
ods. All of the thirteen laboratories reported levels of levoglucosan, whereas nine reported data for mannosan and/or galactosan. Eight of the thirteen laboratories reported levels for all three isomers.

The accuracy for levoglucosan, presented as the mean percentage error (PE) for each participating laboratory, varied from -63 to $20 \%$; however, for $62 \%$ of the laboratories the mean PE was within $\pm 10 \%$, and for $85 \%$ the mean PE was within $\pm 20 \%$. For mannosan, the corresponding range was -60 to $69 \%$, but as for levoglucosan, the range was substantially smaller for a subselection of the laboratories; i.e. for $33 \%$ of the laboratories the mean PE was within $\pm 10 \%$. For galactosan, the mean PE for the participating laboratories ranged from -84 to $593 \%$, and as for mannosan $33 \%$ of the laboratories reported a mean PE within $\pm 10 \%$.

The variability of the various analytical methods, as defined by their minimum and maximum PE value, was typically better for levoglucosan than for mannosan and galactosan, ranging from 3.2 to $41 \%$ for levoglucosan, from 10 to $67 \%$ for mannosan and from 6 to $364 \%$ for galactosan. For the levoglucosan to mannosan ratio, which may be used to assess the relative importance of softwood versus hardwood burning, the variability only ranged from 3.5 to $24 \%$.

To our knowledge, this is the first major intercomparison on analytical methods used to quantify monosaccharide anhydrides in ambient aerosol filter samples conducted and reported in the scientific literature. The results show that for levoglucosan the accuracy is only slightly lower than that reported for analysis of $\mathrm{SO}_{4}^{2-}$ (sulfate) on filter samples, a constituent that has been analysed by numerous laboratories for several decades, typically by ion chromatography and which is considered a fairly easy constituent to measure. Hence, the results obtained for levoglucosan with respect to accuracy are encouraging and suggest that levels of levoglucosan, and to a lesser extent mannosan and galactosan, obtained by most of the analytical methods currently used to quantify monosaccharide anhydrides in ambient aerosol filter samples, are comparable.

Finally, the various analytical methods used in the current study should be tested for other aerosol matrices and concentrations as well, the most obvious being summertime aerosol samples affected by wildfires and/or agricultural fires.

\section{Introduction}

The monosaccharide anhydrides (MAs) levoglucosan, galactosan and mannosan are products of the incomplete combustion and pyrolysis of cellulose and hemicelluloses, and are thus constituents of biomass burning (BB) aerosol (Hornig et al., 1985; Simoneit, 1999). The presence of MAs has been demonstrated in emissions from wood combustion (Oros and Simoneit, 1999; Fine et al., 2001; Nolte et al., 2001; Schmidl et al., 2008; Frey et al., 2009; Gonçalves et al., 2010, 2011; Orasche et al., 2012) as well as from wildfires, prescribed and agricultural fires (dos Santos et al., 2002; Gao et al., 2003; Sillanpää et al., 2005; Mazzoleni et al., 2007; Sullivan et al., 2008; Alves et al., 2010; Saarnio et al., 2010a; Vicente et al., 2012; Wang et al., 2011). Recently, it has been shown that combustion of peat (Iinuma et al., 2007; Kourtchev et al., 2011) as well as of certain types of brown coal (Fabbri et al., 2009) could be additional sources of ambient aerosol concentrations of MAs in regions where such fuels are utilised.

Levoglucosan exhibits the highest concentration of the MAs in BB aerosol; consequently, it has been applied for source apportionment of ambient particulate matter (PM). Additional information can be drawn from the PM MAs pattern, e.g. it has been used to estimate the impact from combustion of different wood types; however, no clear picture of the variability of MAs concentrations and ratios from wood combustion has been found. Some studies have reported a high variability depending on burning conditions or type of wood with filtration-based sampling (Schmidl et al., 2008; Orasche et al., 2012, 2013) or by application of aerosol mass spectrometry (Weimer et al., 2008; Elsasser et al., 2013). Other studies have shown relatively little variation in MAs emissions during wood combustion under varying conditions (Jordan and Seen, 2005; Frey et al., 2009) or with different types of wood (Fine et al., 2001, 2002, 2004). Size distribution measurements of MAs in particulate emission samples from wood combustion have shown that most MAs are associated with $\mathrm{PM}<1.2 \mu \mathrm{m}$ (Frey et al., 2009). These results are in agreement with wintertime observations showing that most levoglucosan is present in the $\mathrm{PM}_{1}$ fraction of the ambient aerosol (Yttri et al., 2005; Agarwal et al., 2010; Krumal et al., 2010).

The atmospheric concentration of levoglucosan is highly variable as it depends not only on the source strength, but also on meteorological parameters. During wintertime in Europe residential wood burning is the major source of levoglucosan, and the observed concentration is typically $<1 \mu \mathrm{g} \mathrm{m}^{-3}$ (Oliveira et al., 2007; Yttri et al., 2009; Krumal et al., 2010; Schnelle-Kreis et al., 2010; Caseiro and Oliveira, 2012; Herich et al., 2014). In the evening and during night-time higher concentrations $\left(>1 \mu \mathrm{g} \mathrm{m}^{-3}\right)$ can be observed (Elsasser et al., 2012; Saffari et al., 2013). Agricultural fires are reported to cause ambient levoglucosan concentrations well above $1 \mu \mathrm{g} \mathrm{m}^{-3}$ (Pietrogrande et al., 2013), and concentrations $>7 \mu \mathrm{g} \mathrm{m}^{-3}$ have been reported for haze episodes in tropical regions (Claeys et al., 2010; He et al., 2010).

Early investigations suggested that levoglucosan is resistant to atmospheric acid-catalysed degradation (Fraser and Lakshmanan, 2000). The low vapour pressure of levoglucosan (Oja and Suuberg, 1999; Booth et al., 2011) as well as the minor impact of temperature on the observed volatility of levoglucosan in ambient PM (Ruehl et al., 2011) further supports its stability and thus its suitability as a tracer species. Recent investigations on the stability of levoglucosan in aqueous solution suggest that "oxidation of levoglu- 
cosan in atmospheric deliquescent particles is at least as fast as that of other atmospherically relevant organic compounds and levoglucosan may not be as stable as previously thought in the atmosphere, especially under high relative humidity conditions" (Hoffmann et al., 2010; Teraji and Arakaki, 2010). Further, oligomerisation of levoglucosan by Fenton chemistry in aqueous solution has been observed (Holmes and Petrucci, 2007). The decay of levoglucosan upon ageing of wood combustion aerosol has been studied in smog chamber experiments. When exposed to typical summertime $\mathrm{OH}$ radical concentrations, the atmospheric lifetime of levoglucosan in BB particles was found to be 0.7-2.2 days (Hennigan et al., 2010) under BB plume conditions and estimated to range up to 2 weeks for atmospheric background conditions (Slade and Knopf, 2013). The impact of the abovementioned effects on the levoglucosan content in the (true) ambient aerosol still remains to be documented; however, these are indications that levoglucosan may be depleted in the atmosphere, and that possible degradation should thus be taken into account when using levoglucosan as a tracer of BB emissions in source apportionment studies. Nonetheless, levoglucosan is a valuable tracer to investigate the impact of residential wood burning in urban (Oliveira et al., 2007; Timonen et al., 2008; Caseiro et al., 2009; Szidat et al., 2009; Bari et al., 2010; Schnelle-Kreis et al., 2010; Saffari et al., 2013), rural background (Gelencsér et al., 2007; Puxbaum et al., 2007, van Drooge and Ballesta, 2009) and remote areas (May et al., 2009; Yttri et al., 2014), especially during winter, when wood combustion is used for domestic heating.

As levoglucosan is commonly used as a tracer of emissions from biomass combustion, increasing efforts have been put into levoglucosan quantification during the last decade. Gas chromatographic methods have been established since the end of the last century, whereas liquid chromatographic methods were more recently developed and have been gaining attention. A review of existing methods was published in 2006 (Schkolnik and Rudich, 2006) and derivatisation methods for analysis of MAs using gas chromatography (GC) were covered by Hsu et al. (2007). Thus, only a brief overview on actual existing methods and developments will be given here.

Gas chromatography-mass spectrometry (GC-MS) methods for separation and quantification of MAs are widespread. Most GC methods used for analysis of MAs in environmental samples make use of solvent extraction followed by trimethylsilylation (Simoneit, 1999; Pashynska et al., 2002; Simpson et al., 2004; Medeiros and Simoneit, 2007). Reactive pyrolysis, i.e. thermally assisted alkylation of MAs, established in pyrolysis research (Fabbri et al., 2002), has also been applied to environmental samples (Blazso et al., 2003), and more recently, thermal extraction methods have been developed. Lin et al. (2007) investigated solid-phase microextraction for pre-concentration of levoglucosan from filter samples prior to GC analysis, whereas Orasche et al. (2011) developed a method for in situ derivatisation of MAs in filter samples followed by GC-MS. The most recent advance was made by Ma et al. (2010), who developed a two-dimensional GC method, which uses heart-cutting and thermal extraction of MAs from filter samples without the need of chemical derivatisation.

High-performance liquid chromatography combined with mass spectrometry (HPLC-MS) and high-performance anion-exchange chromatography (HPAEC) are the most commonly used methods for analysis of MAs in extracts based on polar solvents. Methods such as capillary electrophoresis with pulsed amperometric detection (CE-PAD) (Garcia et al., 2005), chloride attachment in liquid chromatography combined with negative ion electrospray mass spectrometry (Wan and Yu, 2007) and ion-exclusion highperformance liquid chromatography followed by spectroscopic detection (Schkolnik et al., 2005) have been reported in the scientific literature but do not seem to be widely applied to MA analysis. Gao et al. (2003) were the first to report the use of electrospray ionisation mass spectrometry (ESIMS) for quantification of MAs, and, at present, HPLC combined with mass spectrometric (Dye and Yttri, 2005; Larsen et al., 2006; Wan and Yu, 2007; Piot et al., 2012) or aerosol charge detection (HPLC-ACD) (Dixon and Baltzell, 2006) are widespread. HPAEC coupled with pulsed amperometric detection (PAD) (Engling et al., 2006; Caseiro et al., 2007; Iinuma et al., 2009; Piazzalunga et al., 2010) or with mass spectrometric detection (HPAEC-MS) (Saarnio et al., 2010b) have been employed more recently.

The objective of the current intercomparison is to examine the comparability of the great diversity of analytical methods used for analysis of levoglucosan, mannosan and galactosan in ambient aerosol filter samples.

\section{Experimental}

\subsection{Site description and measurement period}

Aerosol filter samples were collected at the urban background site Kjeller $\left(59^{\circ} 58^{\prime} \mathrm{N}, 11^{\circ} 3^{\prime} \mathrm{E}\right)$, on the outskirts of the small town of Lillestrøm (20000 inhabitants), located $20 \mathrm{~km}$ east of Oslo (Norway). The samples were collected during the period 11-16 December 2008. The sampling inlets were installed approximately $4 \mathrm{~m}$ a.g.l.

\subsection{Aerosol filter samples collection, storage, preparation and shipment}

Six ambient aerosol filter samples were provided using two high-volume samplers with total suspended particulate matter (TSPM) inlets collecting aerosols on quartz fibre filters (Munktel MK 360; $150 \mathrm{~mm}$ in diameter; batch number 403743). The instruments were operated at a flow rate of $21.5 \mathrm{~m}^{3} \mathrm{~h}^{-1}$. The sampling time ranged from 24 to $48 \mathrm{~h}$.

After exposure, the filter samples were folded once, with the exposed side facing inwards, wrapped in aluminium foil, 


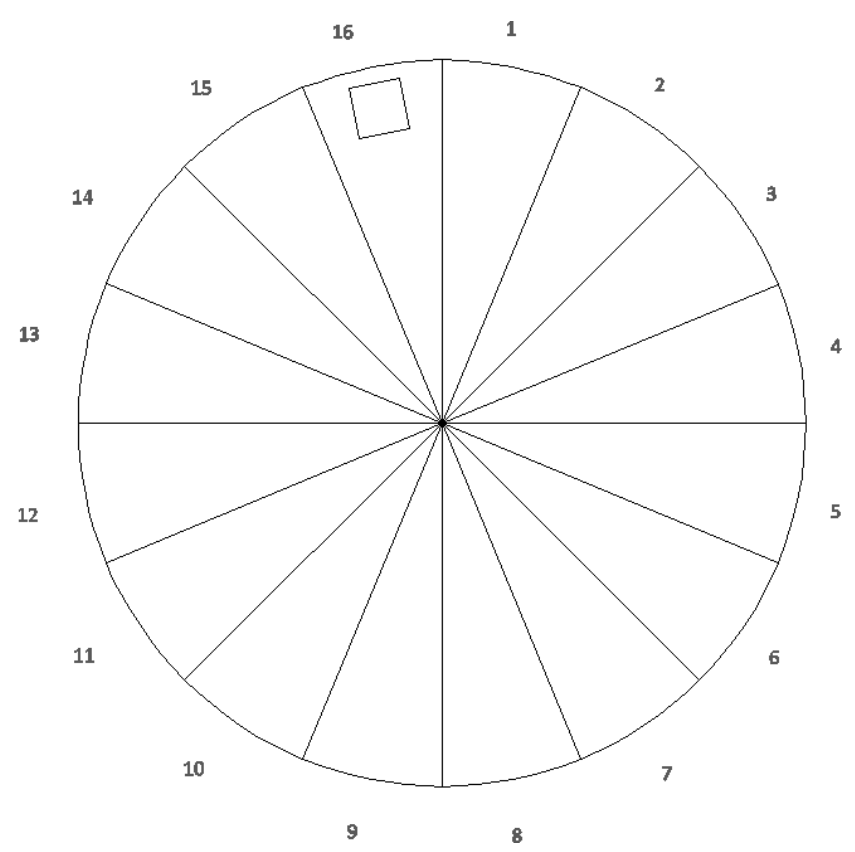

Figure 1. Schematic drawing illustrating the subdivision of one of the six filter samples subjected to the intercomparison. The square in sector 16 illustrates the $1.0 \mathrm{~cm}^{2}$ punch taken from each of the 16 sectors per filter sample to perform a homogeneity test of the filter samples. Each of the sectors sent out to the participating laboratories had an exposed filter area of $8.6 \mathrm{~cm}^{2}$, i.e. when accounting for the removal of the $1.0 \mathrm{~cm}^{2}$ punch.

put in a zip-lock polyethylene bag and stored in a freezer at $-18{ }^{\circ} \mathrm{C}$ to prevent any form of degradation of the analytes. Two field blanks were collected, which were treated in exactly the same manner regarding handling, transport and storage as the filters being exposed.

Each of the sampled filter samples was divided into 16 equally large sectors, providing a total of 96 sectors, each with an exposed area of $9.6 \mathrm{~cm}^{2}$. A $1.0 \mathrm{~cm}^{2}$ punch was taken from each of the 16 sectors to perform a homogeneity test of the filters subjected to the intercomparison (Sect. 2.4.1). Hence, each of the sectors sent to the participating laboratories had an exposed filter area of $8.6 \mathrm{~cm}^{2}$ (Fig. 1).

Each sector was given a number, which combined with the filter sample identification gave the sector a unique identification. The sectors were then assigned to the participating laboratories following a randomising approach.

For shipment, each sector was wrapped in aluminium foil and placed in a petri slide. The six petri slides, to be received by each of the participating laboratories, were placed in a zip-lock polyethylene bag and sent in an envelope to the participants by mail. Those receiving the samples were directed to store them in a freezer at $-18^{\circ} \mathrm{C}$ until analysis. The deadline for reporting the results was set to be within 70 days after shipment.

\subsection{The data set - background, scope and application}

Fifteen laboratories located in twelve different European countries reported their interest in the current intercomparison exercise and received sectors from the filter samples for analysis. Two of the fifteen laboratories did not submit results. Hence, the results presented in the current study are based on the results of thirteen different laboratories. All thirteen laboratories reported levels for levoglucosan, whereas nine reported levels for mannosan and galactosan. Eight of thirteen laboratories reported levels for all three isomers, whereas one reported for levoglucosan and mannosan, and one for levoglucosan and galactosan.

A brief overview of the various analytical methods used by the participating laboratories in the current intercomparison is provided in Table 1, including information about the method's capability to separate the isomeric compounds levoglucosan, mannosan and galactosan, the method's limit of detection (LOD), the instrument being used for separation and detection of the analytes, the solvent(s) used for extraction and whether derivatisation of the analytes was applied. Complementary information can be found in Table B1, including extraction procedure, derivatisation agent and recovery standard. A full description of the various analytical methods can be found in Appendix A: in Sect. A1 for those using HPAEC, Sect. A2 for those using HPLC and ultraperformance liquid chromatography (UPLC) and Sect. A3 for those applying GC.

All of the major methods used for analysis of levoglucosan, mannosan and galactosan in ambient aerosol filter samples, and which have been reported in the scientific literature so far, are represented in the present intercomparison. This adds additional strength to any conclusion to be drawn from the study. In addition, the descriptions of the various methods show that none of them can be considered completely identical; i.e. they differ to a large extent with respect to crucial parameters, such as extraction procedure and derivatisation agent, to fulfil such a criterion. This, however, brings an important asset to the intercomparison, as the goal is to evaluate the comparability of the great diversity of analytical methods used for analysis of levoglucosan, mannosan and galactosan in ambient aerosol filter samples. On the contrary, this great diversity prevents comparison of the performance of different subclasses of analytical methods, e.g. GC-based versus LC-based methods.

\subsection{Quality assurance}

\subsubsection{Homogenity of filter samples}

A uniformity test was performed to ensure that the two colocated filter samplers generated samples with a homogenous distribution of the analytes.

Each of the six filter samples analysed in the intercomparison were divided into 16 equally large sectors. From each 
Table 1. Overview and short description of the analytical methods used by the participating laboratories in the present intercomparison, including the method's capability for isomer separation, the method's limit of detection (LOD), the instrument used for separation and detection of the analytes, the solvent(s) used for extraction and whether derivatisation of the analytes was applied.

\begin{tabular}{llrlll}
\hline Lab no. & $\begin{array}{l}\text { Isomer } \\
\text { separation }\end{array}$ & $\begin{array}{r}\text { LOD } \\
\left(\mathrm{ng} \mathrm{m}^{-3}\right)^{1}\end{array}$ & Instrument & Solvent & Derivatisation \\
\hline 1 & Yes & 0.28 & HPLC-HR-TOFMS (ESI-) & tetrahydrofuran & No \\
2 & Yes & 2.2 & IC-QMS (ESI-) & deionised $\mathrm{H}_{2} \mathrm{O}$ & No \\
3 & Yes & 5.0 & HPAEC-PAD & methised $\mathrm{H}_{2} \mathrm{O}$ & No \\
4 & Yes & 0.05 & GC-MS & dichloromethane/methanol & Yes \\
5 & No & 0.05 & GC-QMS & methanol & No \\
6 & Yes & 1.8 & LC-MS (ESI+) & deionised $\mathrm{H}_{2} \mathrm{O}$ & No \\
7 & Yes & 0.004 & HPAEC-PAD & deionised $\mathrm{H}_{2} \mathrm{O}$ & No \\
8 & Yes & 3.0 & LC-MS-MS (ESI-) & dichloromethane/methanol & Yes \\
9 & Yes & 0.02 & GC-MS & deionised $\mathrm{H}_{2} \mathrm{O} /$ methanol & No \\
10 & Yes & 0.19 & UPLC-MS-MS & dichloromethane/methanol & Yes \\
11 & Yes & 0.02 & GC-MS & none & Yes \\
12 & Yes & 0.004 & TD-GC-TOFMS & dichloromethane/methanol & Yes \\
13 & Yes & 0.05 & GC-QMS & & \\
\hline
\end{tabular}

LOD calculated for an air volume of $2.3 \mathrm{~m}^{3} \mathrm{~h}^{-1}$ for 24 hours and an exposed filter area of $12 \mathrm{~cm}^{2}$. For explanation of abbreviations see Table $\mathrm{C} 1$.

sector one $1.0 \mathrm{~cm}^{2}$ punch was taken and subjected to levoglucosan, mannosan and galactosan analysis using the analytical method applied by lab. 1 (See Appendix A for a detailed description of the analytical methods used by the participating laboratories), i.e. a total of 96 analyses were performed for each of the three isomers. The results from this uniformity test are shown in Table B2 and are briefly summarised as follows.

For levoglucosan, the mean relative standard deviation (RSD) for all six filter samples was $11 \pm 2.7 \%$. The highest RSD was observed for filter sample $3(16 \%)$ and the lowest for filter sample $2(9.1 \%)$. For mannosan, the mean RSD was $19 \pm 9.9 \%$, with the lowest RSD for filter sample $1(10 \%)$ and the highest for filter sample $4(35 \%)$. For galactosan, the mean RSD was $24 \pm 15 \%$, with the lowest RSD for filter sample $2(11 \%)$ and the highest for filter sample $3(45 \%)$. Note that the percentage provided for the RSD also includes the uncertainty of the analytical method (which is $<5 \%$ ); hence, the filter homogeneity is in fact up to $5 \%$ lower than that stated above. Two outliers were detected for galactosan (one in filter sample 4 and one in filter sample 5) and one for mannosan (filter sample 5), when running the Grubbs test for outliers. These outliers did not affect the results of the intercomparison, as the sectors from which they were taken were sent out to laboratories which either did not submit results at all or which did not submit results for mannosan (lab. 13), or the sector was not assigned to any of the participating laboratories. Consequently, the results from the homogeneity test demonstrate that the collected filter samples are sufficiently homogenous to be used for an intercomparison.

Finally, it can be questioned to which extent a $1.0 \mathrm{~cm}^{2}$ punch from each sector is representative for addressing the homogeneity of the filter samples as it accounts for no more than $10 \%$ of the total exposed filter area. However, the size of the punch used for the homogeneity test should not compromise the participation of laboratories using analytical methods with detection limits varying over a wide range.

\subsubsection{Outliers - Grubbs test}

The Grubbs test was used to detect outliers amongst the results submitted by the various laboratories. For levoglucosan, one outlier was detected for filter samples 1 and 2 and both were reported by the same laboratory (lab. 7). For galactosan, one outlier was detected for each of the six filter samples and all were reported by the same laboratory (lab. 9). No outliers were observed for mannosan. Values defined as outliers were excluded from calculation of the theoretical median value, but included in the measured arithmetic mean value (see Sect. 2.5 for explanation of theoretical and measured value).

\subsubsection{Samples with levels below limit of detection}

Two laboratories (labs. 3 and 8) reported values of galactosan below the established detection limit of their analytical method for filter samples 3-6. These values were not included in the calculated theoretical median value nor in the measured mean value.

\subsection{Calculation of the analytical methods performance}

The outcomes of the intercomparison are presented in Figs. 2-4 as aggregated results, whereas the aggregated data reported by the laboratories, which are used as input for Figs. 2-4, are listed in Table B3. The results are presented in terms of the percentage error (PE); i.e. the PE was calcu- 


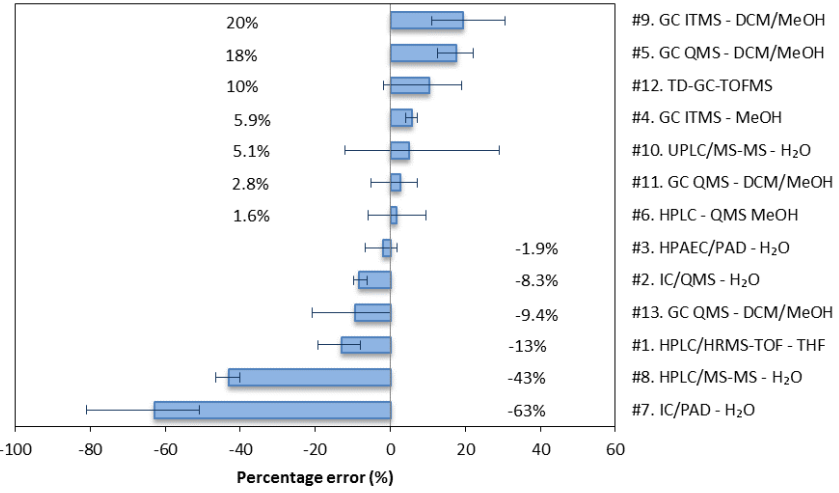

Figure 2. Calculated mean percentage error (PE) for each of the thirteen laboratories reporting levels of levoglucosan in the current intercomparison. The PE was calculated according to Eq. (1) (Sect. 2.5) for each of the six sectors received by the participating laboratories. The mean PE for each laboratory accounts for the PE calculated for all six sectors. The laboratory number, ranging from $1-13$, the analytical method and solvent used for extraction are mentioned at the right of the figure.

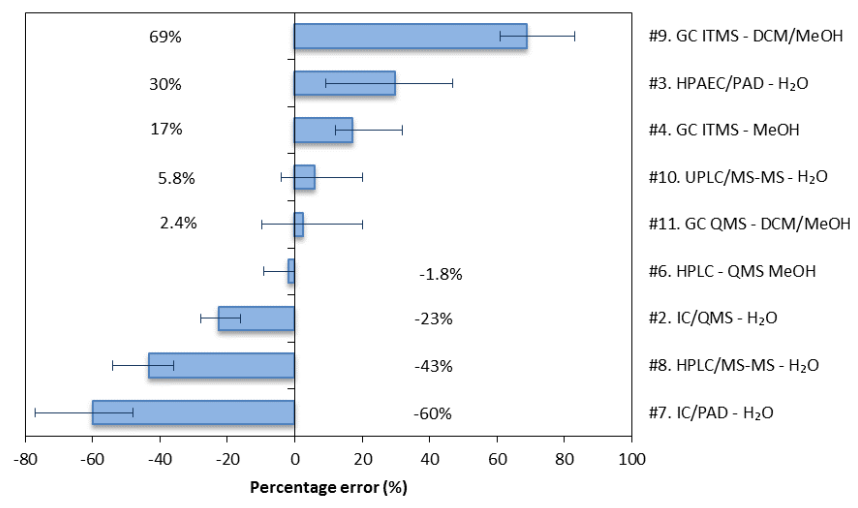

Figure 3. Calculated mean percentage error (PE) for each of the nine laboratories reporting levels of mannosan in the current intercomparison. The PE was calculated according to Eq. (1) (Sect. 2.5) for each of the six sectors received by the participating laboratories. The mean PE for each laboratory accounts for the PE calculated for all six sectors. The laboratory number, ranging from 1-13, the analytical method and solvent used for extraction are mentioned at the right of the figure.

lated for each of the participating laboratories for each of the six filter samples according to Eq. (1). The arithmetic mean PE for each laboratory, accounting for all six filters, was then subsequently calculated (Figs. 2-4).

Percentage error $(\mathrm{PE})=$

$\frac{\text { Measured }- \text { Theoretical }}{\text { Theoretical }} \times 100$,

where measured is the value of the analyte, e.g. levoglucosan, reported by the actual laboratory for one of the six filter samples and which is having its accuracy tested versus

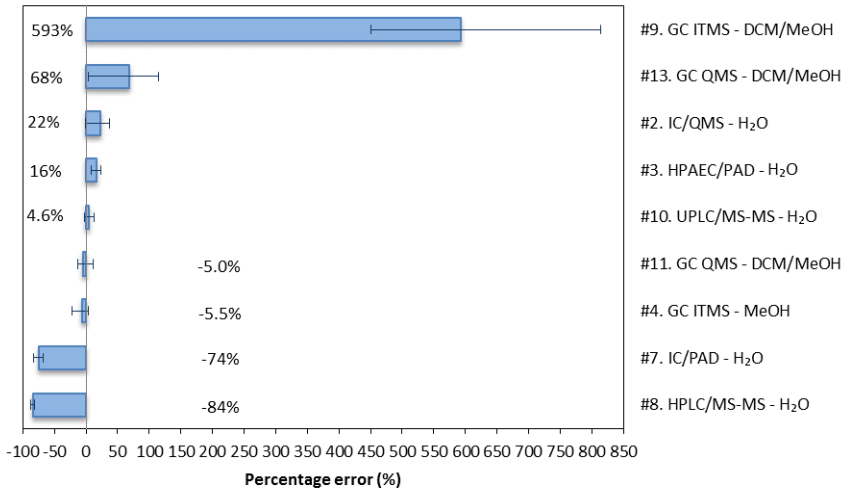

Figure 4. Calculated mean percentage error (PE) for each of the nine laboratories reporting levels of galactosan in the current intercomparison. The PE was calculated according to Eq. (1) (Sect. 2.5) for each of the six sectors received by the participating laboratories. The mean PE for each laboratory accounts for the PE calculated for all six sectors. The laboratory number, ranging from 1-13, the analytical method and solvent used for extraction are mentioned at the right in the figure.

the theoretical value. The latter value is the median value of the analyte based on the values reported by all participating laboratories (except outliers as described above). For laboratories reporting values for two or more aliquots per sector, the measured value is represented by the arithmetic mean, as this variable better reflects the variability of the method's performance. For the theoretical value we chose to use the median in order to limit the influence of deviating results not considered as outliers.

The isomer splits, which show the relative contribution of each of the three monosaccharide anhydrides to the sum of the three monosaccharide anhydrides ( $\Sigma \mathrm{MA})$, and the levoglucosan to mannosan ratio are shown in Figs. 5-8 as aggregated results, whereas the aggregated data, based on those reported by the laboratories, are listed in Table B4. The results are discussed in detail in Sect. 3.

\subsection{Analytical standard compounds}

A different quality of standard compounds is a factor potentially affecting the comparability of an intercomparison. Results obtained using standard compounds without a given purity are of particular concern, but also batch-to-batch inconsistency is of potential importance.

In the present study, quantification standards of levoglucosan from three different manufacturers were employed, ranging from $>98$ to $99 \%$ purity. For mannosan the range of purity was $98 \%$ to purity not given for standards purchased from three different manufacturers. One of the laboratories (lab. 11) used the levoglucosan standard also for mannosan and galactosan. The purity of the galactosan standards was not provided for all, except for that used by lab. 9 (98\% purity) and lab. 13 (99\% purity). 


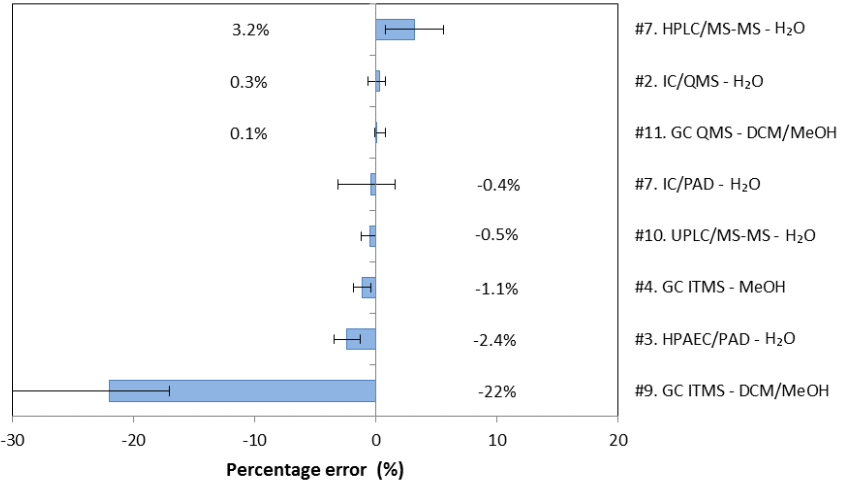

Figure 5. Calculated mean percentage error (PE) for each of the eight laboratories for which the levoglucosan to $\Sigma \mathrm{MA}$ ratio could be derived. The PE was calculated according to Eq. (1) (Sect. 2.5) for each of the six sectors received by the participating laboratories. The mean PE for each laboratory accounts for the PE calculated for all six sectors. The laboratory number, ranging from 1 to 13 , the analytical method and solvent used for extraction are mentioned at the right of the figure.

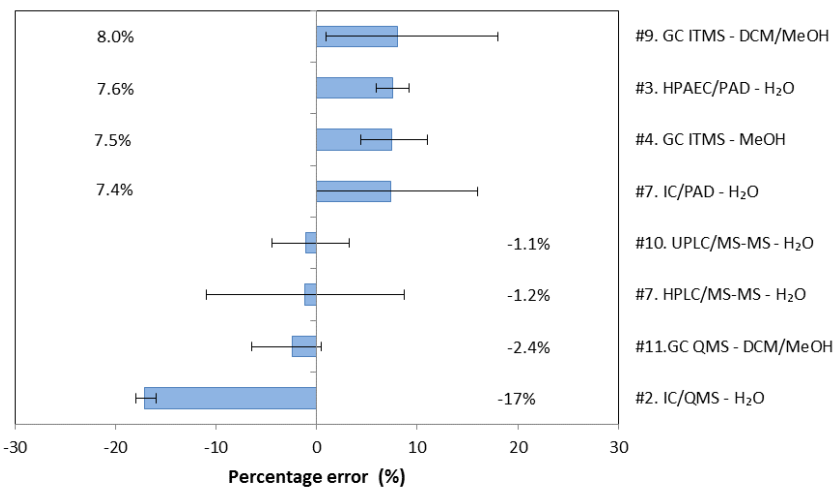

Figure 6. Calculated mean percentage error (PE) for each of the eight laboratories for which the mannosan to $\Sigma \mathrm{MA}$ ratio could be derived. The PE was calculated according to Eq. (1) (Sect. 2.5) for each of the six sectors received by the participating laboratories. The mean PE for each laboratory accounts for the PE calculated for all six sectors. The laboratory number, ranging from 1 to 13 , the analytical method and solvent used for extraction are mentioned at the right of the figure.

Nine (labs. 1, 2, 4, 5, 6, 9, 11, 12 and 13) out of the thirteen laboratories used an internal standard, but only eight (labs. 1, $2,4,5,6,9,11$ and 12) of them used it to account for potential loss of analytic compounds during the sample preparation process. ${ }^{13} \mathrm{C}_{6}$-labeled levoglucosan with a $98-99 \%$ purity, purchased from two different manufacturers, was used by four laboratories (labs. 1, 2, 6, 12), whereas ${ }^{2} \mathrm{H}_{7}$-labeled levoglucosan (99\% purity) (lab. 9), ${ }^{13} \mathrm{C}_{6}$-labeled galactosan (purity not known) (lab. 1), ${ }^{2} \mathrm{H}_{4}$-labeled succinic acid (98\% purity) (lab. 5), $O$-L-xylanopyranoside (99\% purity) (lab. 4) and sedoheptulose (>99\% purity) (lab. 11) were each used

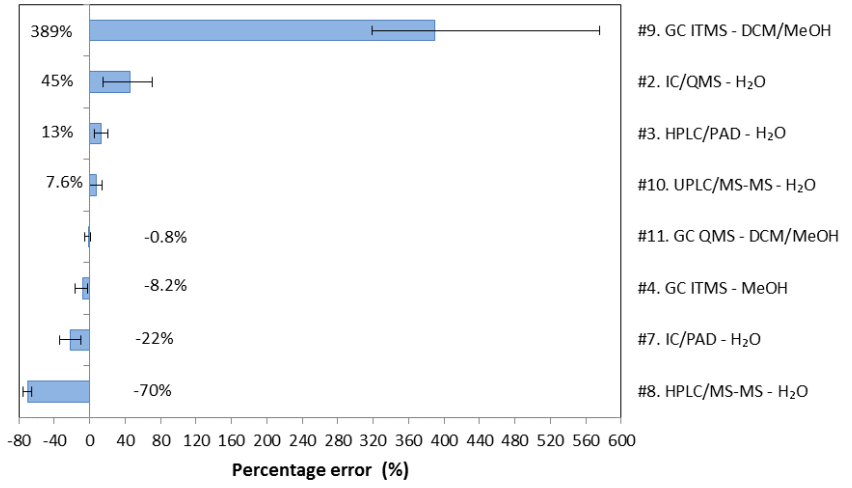

Figure 7. Calculated mean percentage error (PE) for each of the eight laboratories for which the galactosan to $\Sigma$ MA ratio could be derived. The PE was calculated according to Eq. (1) (Sect. 2.5) for each of the six sectors received by the participating laboratories. The mean PE for each laboratory accounts for the PE calculated for all six sectors. The laboratory number, ranging from 1 to 13 , the analytical method and solvent used for extraction are mentioned at the right of the figure.

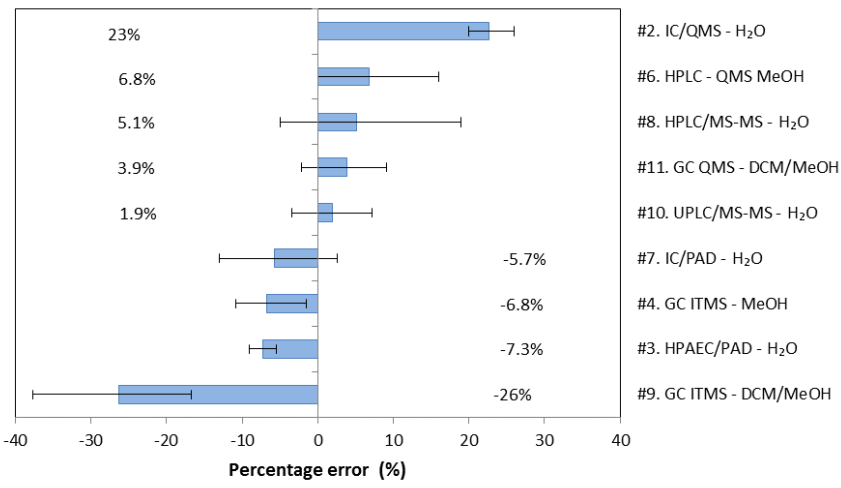

Figure 8. Calculated mean percentage error (PE) for each of the nine laboratories for which the levoglucosan to mannosan ratio could be derived. The PE was calculated according to Eq. (1) (Sect. 2.5) for each of the six sectors received by the participating laboratories. The mean PE for each laboratory accounts for the PE calculated for all six sectors. The laboratory number, ranging from 1 to 13 , the analytical method and solvent used for extraction are mentioned at the right of the figure.

by one laboratory. Laboratory 13 used the internal standard (1-phenyldodecane, $99 \%$ purity) to account for uncertainties in the injection volume.

\section{Results and discussion}

\subsection{Levoglucosan}

The median theoretical concentration of levoglucosan, calculated based on the values reported by the laboratories performing analysis of the actual compound, ranged from 
$552 \mathrm{ng} \mathrm{cm}^{-2}$ (filter sample 6) to $1765 \mathrm{ng} \mathrm{cm}^{-2}$ (filter sample 1) (Table B3). This range corresponds to an ambient concentration of levoglucosan ranging from 120 to $384 \mathrm{ng} \mathrm{m}^{-3}$, assuming a typical low-volume sampler operating at a flow rate of $2.3 \mathrm{~m}^{3} \mathrm{~min}^{-1}$ for $24 \mathrm{~h}$, assuming an exposed filter area of $12 \mathrm{~cm}^{2}$. This is within the range $\left(60-900 \mathrm{ng} \mathrm{m}^{-3}\right)$ observed for European urban areas during wintertime sampling, as reported by Szidat et al. (2009).

For the laboratories extracting, analyzing and reporting values for two or more aliquots per sector, the repeatability was on average $4.5 \pm 2.9 \%$. The repeatability exceeded $10 \%$ for three of the 54 sectors, each of the three being analysed by different laboratories (labs. 1, 3 and 13).

From Fig. 2 it can be seen that the mean PE for the various analytical methods ranged from -63 to $20 \%$, i.e. reflecting the accuracy of the various methods. The lowest mean PE was seen for lab. 7, for which two outliers were detected. When excluding these results from the calculation, the mean PE for lab. 7 improved from -63 to $-54 \%$, and thus also the total range including all the methods. The mean PE was within $\pm 10 \%$ for eight (labs. 2, $3,4,6,10,11,12$ and 13) of the thirteen laboratories, i.e. for $62 \%$ of the laboratories, which should be considered a narrow range, and within $\pm 20 \%$ for eleven (labs. 1 , $2,3,4,5,6,9,10,11,12,13)$ of the thirteen laboratories, corresponding to $85 \%$. Indeed, the accuracy reported for levoglucosan analysis is only slightly lower than the results reported for analysis of $\mathrm{SO}_{4}^{2-}$ on filter samples during the latest intercomparison (intercomparison number 30) organised by EMEP (Co-operative programme for monitoring and evaluation of the long-range transmissions of air pollutants in Europe) (http://www.nilu.no/projects/ccc/ intercomparison/DQO-luft-30.pdf); i.e. an accuracy ranging from -23 to $40 \%$ for the entire data set of 64 laboratories, and from -6 to $5 \%$ for the subselection accounting for $62 \%$ of the laboratories. $\mathrm{SO}_{4}^{2-}$ in aerosol filter samples has been analysed by numerous laboratories for several decades, typically by ion chromatography, and should be considered as a fairly easy constituent to analyse. Hence, the comparable results obtained for levoglucosan with respect to accuracy are encouraging.

In Figs. 2-4 the error bars represent the minimum and the maximum PE observed for the six samples analysed with the respective analytical method. Hence, the range is a measure of the variability of the analytical method; i.e. the smaller the range, the better. For levoglucosan the variability ranged from 3.2 to $41 \%$. Two of the laboratories had a mean PE exceeding $-40 \%$. For lab. 7 the low accuracy was accompanied by a large variability $(30 \%)$, whereas this was not the case for lab. $8(6.5 \%)$. For lab. 7 the combination of a low accuracy and a large variability could suggest an instrument malfunction rather than a flaw in the analytical method used. However, two of the samples reported by this laboratory were outliers, and when excluded from the calculation, the variability improved substantially (i.e. a variability of $5 \%$ ); thus, a systematic underestimation could not be excluded. It should be noted that lab. 7 later found that their instrument suffered from a technical problem that caused a random loss of signals during the sample analysis. Subsequent tests revealed that previous injections of high salt-containing samples (i.e. seawater) had contaminated the instrument. The problem was resolved by a rigorous cleaning of instrument components, including working electrode, tubing and fittings. Nevertheless, only two of the samples reported by this laboratory were considered outliers when tested; hence, the results reported from this laboratory should be included in the current data set. There were also other laboratories experiencing difficulties of various categories during the intercomparison; e.g. lab. 1 experienced possible ion suppression, mainly of levoglucosan, which was not previously observed using the actual method, causing negatively biased concentrations as well as deviating isomer splits. Furthermore, other analytic methods used in the current intercomparison could be affected by flaws as well, except that they have passed unseen. Thus, selectively removing data from the intercomparison when being aware of certain problems for one laboratory but not for others cannot easily be done without introducing additional flaws to the data set.

Despite the fact that the great diversity of the analytical methods prevents us from comparing the performance of different subclasses of analytical methods, it cannot be neglected that a certain pattern emerges from Fig. 2. Five out of the six GC-based methods participating in the intercomparison had a mean PE above the theoretical value, ranging from 2.8 to $20 \%$. Furthermore, four of these five GC methods were based on the approach initially developed in the USA, which subsequently has been adopted by European research laboratories, involving separation by GC, detection by mass spectrometry, extraction by methanol or dichloromethane, or a combination of the two, as well as derivatisation to improve the (gas) chromatographic behaviour of the analyte. Despite a certain variation between laboratories, the general approach outlined above is by far the most commonly used one for analyzing levoglucosan within the research community and it also has the longest record of use. Hence, refinement and experience in using this method is expected to be more extensive than for the more recently developed LC and ion chromatography (IC) methods, for which the mean PE was below the theoretical value for five of seven methods ( -63 to $-1.9 \%$ ) (Fig. 2). Consequently, we should not exclude the possibility that the experience associated with a more widespread analytical method could have a profound influence on the observed pattern, and that this might be an equally important factor as any differences attributed to the choice of the analytical method itself. Given that the more recently developed LC and IC methods have been taken into service on a wider scale than at the time of the current intercomparison, a follow-up intercomparison should address any potential change in the pattern seen in Fig. 2 of the current study. 


\subsection{Mannosan}

The median theoretical concentration of mannosan, calculated based on the values reported by the laboratories performing analysis of the actual compound, ranged from $80 \mathrm{ng} \mathrm{cm}^{-2}$ (filter sample 4) to $300 \mathrm{ng} \mathrm{cm}^{-2}$ (filter sample 1). This range corresponds to an ambient concentration of mannosan ranging from 17 to $65 \mathrm{ng} \mathrm{m}^{-3}$, assuming a typical low-volume sampler operating at a flow rate of $2.3 \mathrm{~m}^{3} \mathrm{~h}^{-1}$ for $24 \mathrm{~h}$, assuming an exposed filter area of $12 \mathrm{~cm}^{2}$.

For the laboratories extracting, analyzing and reporting values of mannosan for two or more aliquots per sample, the repeatability was on average $5.2 \pm 3.9 \%$. The repeatability exceeded $10 \%$ for three of the 36 samples, and was reported by two different laboratories (labs. 8 and 9).

The mean PE, representing the accuracy, ranged from -60 to $69 \%$ for the various analytical methods reporting values for mannosan (Fig. 3). This range is noticeably wider than that seen for levoglucosan (-63 to $20 \%$ ), and whereas $62 \%$ of the laboratories reported a mean PE within $\pm 10 \%$ for levoglucosan, the corresponding percentage for mannosan was only 33 (i.e. for labs. 6, 10 and 11); $55 \%$ of the laboratories reported a mean PE within $\pm 23 \%$ for mannosan (labs. 2, 4, 6, 10 and 11).

As described in Sect. 4.1, the error bars in Figs. 2-4 represent the minimum and the maximum PE observed for the actual analytical method, and thus the range is a measure of the variability of the analytical method. For mannosan the variability ranged from 9.3 to $38 \%$, which is a slightly smaller range than that seen for levoglucosan. For five of the nine laboratories (labs. 2, 3, 4, 8 and 11) reporting values for both levoglucosan and mannosan the variability was substantially higher, i.e. a factor of 2-6 for mannosan compared to levoglucosan. For two of the laboratories the difference was only minor (lab. 9) or non-existent (lab. 7), whereas labs. 6 and 10 had a slightly lower variability for mannosan compared to levoglucosan.

The three GC-based methods used to determine levels of mannosan had a mean PE above the theoretical value, ranging from 2.4 to $69 \%$, thus reflecting the general pattern seen for levoglucosan, whereas it ranged from below to above the theoretical values for the LC-based and IC-based methods.

\subsection{Galactosan}

The median theoretical concentration of galactosan, calculated based on the values reported by the laboratories performing analysis of the actual compound, ranged from $31 \mathrm{ng} \mathrm{cm}^{-2}$ (filter sample 6) to $90 \mathrm{ng} \mathrm{cm}^{-2}$ (filter sample 1). This range corresponds to an ambient concentration of galactosan ranging from 7 to $20 \mathrm{ng} \mathrm{m}^{-3}$, assuming a typical lowvolume sampler operating at a flow rate of $2.3 \mathrm{~m}^{3} \mathrm{~h}^{-1}$ for $24 \mathrm{~h}$, assuming an exposed filter area of $12 \mathrm{~cm}^{2}$.

For the laboratories extracting, analyzing and reporting values for two or more aliquots per sample, the repeatabil- ity was on average $8.5 \pm 11 \%$. The repeatability exceeded $10 \%$ for eleven of the 34 samples, and was reported by five different laboratories (labs. 2, 3, 8, 9 and 11).

The mean PE, representing the accuracy, ranged from -84 to $593 \%$ for the various analytical methods reporting values for galactosan. This range is noticeably wider than that seen for both levoglucosan (-63 to $20 \%$ ) and mannosan (-60 to $69 \%)$. The very high mean PE (593\%) seen for lab. 9 is consistent with the finding that all values of galactosan reported by this laboratory were found to be outliers. When excluding these data from the calculation, the mean PE range is substantially narrowed $(-84-68 \%)$, but it is still wider than for the two other isomers. Excluding the two outliers reported by lab. 7 did not have an influence on the mean PE range including all laboratories, and it only marginally improved the mean PE for lab. 7, going from -74 to $-70 \% ; 33 \%$ of the laboratories (labs. 4, 10, and 11) reported a mean PE for galactosan within $\pm 10 \%$. This equals the percentage found for mannosan, but it is substantially lower than that observed for levoglucosan (62\%); $55 \%$ of the laboratories (labs. 2, 3, 4,10 , and 11) reported a mean PE within $\pm 22 \%$ for galactosan. It should be noted that for labs. 3 and 8, the mean PE is based on the results from only two of the six filter samples, as the value was found to be below the detection limit (BDL) for the other four.

As previously described (Sects. 4.1 and 4.2), the error bars in Figs. 2-4 represent the minimum and the maximum PE observed for the actual analytical method, and thus are a measure of the variability. For galactosan the variability ranged from 6 to $364 \%$ when including all laboratories. For the subselection of laboratories not influenced by outliers or levels below the detection limit, the variability ranged from 16 to $112 \%$. For the latter subcategory of laboratories the variability for galactosan was better than that seen for mannosan for two of the laboratories (labs. 10 and 11) and poorer for the two others (labs. 2 and 4). For lab. 10, the variability was noticeably better for galactosan $(16 \%)$ also when compared to levoglucosan (41 and $31 \%$ for levoglucosan and mannosan, respectively).

\subsection{Relative contribution of levoglucosan, mannosan and galactosan to the sum of the three isomeric compounds ( $\mathbf{M A})$}

\subsubsection{Levoglucosan to $\Sigma M A$ ratio}

The median theoretical relative contribution of levoglucosan to $\Sigma$ MA ranged from 81 to $83 \%$ for the eight laboratories from which this ratio could be derived (Table B4); i.e. laboratories not affected by outliers of any of the three isomers or by levels below detection limit (Table B3). The levoglucosan to $\Sigma$ MA ratio did not vary substantially between the laboratories included in the above-mentioned subcategory. The largest difference was observed for filter sample 1 for which lab. 3 and lab. 10 reported a value of $81 \%$ and lab. 8 a value 
of $87 \%$. This rather small difference is to be expected given that levoglucosan is by far the major MA of the three isomeric compounds reported in the literature. Lab. 7 reported values of levoglucosan for filter samples 1 and 2 , which were found to be outliers; however, the levoglucosan to $\Sigma \mathrm{MA}$ ratio for these two filter samples $(80 \%)$ did not differ substantially from that of filter samples 3-6 (82-84\%) nor from the subcategory not affected by outliers. For lab. 9 the levoglucosan to $\Sigma$ MA ratio ranged from 57 to $69 \%$, which is substantially lower than for the other laboratories. Indeed, lab. 9 reported levels of galactosan for filter samples 1-6, which all were found to be outliers, and a markedly high mean PE for galactosan of $593 \%$ (Fig. 4). Laboratory 9 also reported the highest mean concentration of mannosan, with a mean PE of $69 \%$ (Fig. 3). Despite the fact that lab. 9 also reported the highest mean concentration of levoglucosan, the mean PE $(20 \%)$ was lower for this isomer than for the two others; hence, the lower levoglucosan to $\Sigma$ MA ratios seen for lab. 9 can likely be attributed to an overestimation of mannosan and galactosan.

The mean PE, representing the accuracy, ranged from -22 to $3.2 \%$ for the various laboratories for which the levoglucosan to $\Sigma$ MA could be derived (Fig. 5). When excluding lab. 9, which reported outliers for filter samples 1-6 with respect to galactosan, this range is substantially reduced $(-2.4$ to $3.2 \%$ ). Excluding the two outliers detected for lab. 7 only had a minor effect on the mean PE for the actual laboratory, going from -0.4 to $-0.6 \%$.

As described in Sects. 4.1-4.3, the error bars in Figs. 2-8 represent the minimum and the maximum PE observed for the actual analytical method, and thus are a measure of the method's variability. For the levoglucosan to $\Sigma$ MA ratio the variability ranged from 0.9 to $13 \%$ when including all laboratories. For the subselection of laboratories not influenced by outliers, the variability ranged from 0.9 to $4.8 \%$.

\subsubsection{Mannosan to $\Sigma M A$ ratio}

The median theoretical relative contribution of mannosan to $\Sigma$ MA ranged from 13 to $14 \%$ for the laboratories from which this ratio could be derived; i.e. laboratories not affected by outliers of either of the three isomers or by levels below the detection limit. The mannosan to $\Sigma$ MA ratio did not vary substantially between the laboratories included in the above-mentioned subcategory. The largest difference was observed for filter sample 1 for which lab. 2 reported a value of $11 \%$ and labs. 1 and 3 a value of $15 \%$. Lab. 7 reported values of levoglucosan for filter samples 1 and 2, which were considered outliers, hence, potentially affecting the $\Sigma$ MA value and the mannosan to $\Sigma$ MA ratio. The mannosan to $\Sigma$ MA ratio for these two filter samples $(16 \%)$ did not differ substantially from that of filter samples 3-6 (13$16 \%$ ), while they were slightly higher compared to the subcategory not affected by outliers. Lab. 9 reported levels of galactosan for filter samples 1-6 which all were considered to be outliers; however, the mannosan to $\Sigma$ MA ratio (14$17 \%$ ) did not experience a similar decrease as the levoglucosan to $\Sigma$ MA ratio due to the substantially elevated concentrations of galactosan; on the contrary, they were in the upper range and above that seen for the subcategory not affected by outliers; i.e. the mean PE of $69 \%$ seen for lab. 9 with respect to mannosan seems to have counteracted this.

The mean PE, representing the accuracy, ranged from -17 to $8 \%$ for the various laboratories for which the mannosan to $\Sigma$ MA could be derived (Fig. 6). Excluding lab. 9, which reported outliers for filter samples 1-6 with respect to galactosan, and lab. 7, which reported outliers for filters 1 and 2 for levoglucosan, did not have an influence on the reported range. Excluding the two outliers detected for lab. 7 improved the mean PE for the actual laboratory from 7.4 to $3.4 \%$.

As previously described, the error bars in Figs. 2-8 represent the minimum and the maximum PE observed for the actual analytical method, and thus are a measure of the method's variability. For the mannosan to $\Sigma$ MA ratio the variability ranged from 2 to $20 \%$ when including all laboratories. The range did not change for the subselection of laboratories not influenced by outliers.

\subsubsection{Galactosan to $\Sigma \mathrm{MA}$ ratio}

The median theoretical relative contribution of galactosan to $\Sigma$ MA ranged from 3.9 to $5.0 \%$ for the laboratories from which this ratio could be derived; i.e. laboratories not affected by outliers of either of the three isomers or by levels below the detection limit. The galactosan to $\Sigma$ MA ratio varied more between laboratories than seen for the two other isomers considering the above-mentioned subcategory. The largest difference was observed for filter sample 1 for which lab. 2 reported a value of $6.3 \%$ and lab. 8 a value of $1.0 \%$. Lab. 7 reported values of levoglucosan for filter samples 1 and 2, which were considered outliers, hence, potentially affecting the $\Sigma \mathrm{MA}$ value and the galactosan to $\Sigma \mathrm{MA}$ ratio. The mannosan to $\Sigma$ MA ratio for these two filter samples (3.5-3.6\%) was in the upper range of that seen for filter samples 3-6 (2.6-3.5\%), whereas they were slightly lower compared to the subcategory not affected by outliers. Lab. 9 reported levels of galactosan for filter samples 1-6 which all were found to be outliers. The elevated levels reported by lab. 9 with respect to galactosan also had an effect on the galactosan to $\Sigma$ MA ratio, which ranged from 17 to $27 \%$, being substantially higher than for the subcategory not affected by outliers.

The mean PE, representing the accuracy, ranged from -70 to $389 \%$ for the various laboratories for which the galactosan to $\Sigma$ MA could be derived (Fig. 7). Excluding lab. 9, which reported outliers for filter samples 1-6 with respect to galactosan, substantially narrowed the range $(-70-45 \%)$, whereas no change was observed when excluding lab. 7 , which reported outliers for filter samples 1 and 2 for levoglu- 
cosan. Excluding the two outliers detected for lab. 7 changed the mean PE for the actual laboratory from -22 to $-26 \%$. It should be noted that for lab. 8 , the mean PE $(-70 \%)$ is based on filter samples 1 and 2 only, as galactosan for filter samples 3-6 was found to be below the detection limit.

The error bars in Figs. 2-8 represent the minimum and the maximum PE observed for the actual analytical method, and thus are a measure of the method's variability. For the galactosan to $\Sigma$ MA ratio the variability ranged from 6 to $257 \%$ when including all laboratories. The range was substantially narrowed (6-56\%) when excluding lab. 9, which reported outliers for filter samples 1-6 with respect to galactosan. Excluding lab. 7, which reported outliers for filter samples 1 and 2 for levoglucosan, did not have an effect on the total range.

\subsection{The levoglucosan to mannosan ratio}

The levoglucosan to mannosan ratio is occasionally used to apportion the contribution of residential wood burning emissions to burning of either softwood or hardwood (Caseiro et al., 2009; Favez et al., 2010; Piazzalunga et al., 2011; Maenhaut et al., 2012), with softwood combustion giving rise to low ratios $(<4)$ and hardwood to high ratios (14-15) (Schmidl et al., 2008). The latter authors proposed the following equation to derive the $\%$ spruce (or softwood) burnt (relative to the total amount of softwood + hardwood burnt):

$\%$ spruce $=(14.8-$ levoglucosan $/$ mannosan $) / 0.112$,

where levoglucosan/mannosan is the levoglucosan to mannosan ratio in the ambient aerosol.

This equation was derived from data that were obtained for the combustion of common hardwood (beech and oak) and softwood species (spruce and larch) in wood stoves in Austria. Besides differences in the levoglucosan to mannosan ratio between various softwood and hardwood species, the uncertainty of the analytical methods used to quantify levoglucosan and mannosan is an unknown variable potentially contributing to the overall uncertainty when performing the softwood and hardwood attribution.

The median levoglucosan to mannosan ratio did not vary much between the six filter samples collected, ranging from 5.3 to 6.2 (Table B4), suggesting a rather stable composition of the wood burnt that impacted the sampling site. When comparing the laboratories from which this ratio could be extracted, i.e. laboratories not affected by outliers for either of the two isomers or by levels below the detection limit, the largest difference observed was seen for filter sample 5 for which lab. 2 reported a levoglucosan to mannosan ratio of 6.9 and lab. 9 a value of 3.6. Lab. 7 reported values of levoglucosan for filter samples 1 and 2, which were considered outliers, thus potentially affecting the levoglucosan to mannosan ratio. The levoglucosan to mannosan ratio for these two filter samples (4.9-5.0) was in the lower range of that of filter samples 3-6 (5.1-6.5) as well as being lower compared to the subcategory not affected by outliers.
The mean PE, representing the accuracy, ranged from -26 to $23 \%$ for the various analytical methods from which the levoglucosan to mannosan ratio could be derived (Fig. 8). In all, $78 \%$ of the laboratories (labs. 3, 4, 6, 7, 8, 10, and 11) reported a mean $\mathrm{PE}$ for the levoglucosan to mannosan ratio within $\pm 7 \%$, which should be considered quite a narrow range. Excluding the two outliers detected for lab. 7 changed the mean PE for the actual laboratory from -5.7 to $-1.5 \%$, thus having no effect on the range including all laboratories.

Assuming that the levoglucosan to mannosan ratio can thus be measured to within $\pm 7 \%$, one can estimate the uncertainty from the analysis on the $\%$ spruce result derived from Eq. (2). This uncertainty is $\pm 8 \%$ spruce points for levoglucosan to mannosan ratios close to $14.8 \%$ (thus for $\%$ spruce values close to $0 \%$ ) and gradually decreases to $\pm 2 \%$ spruce points for ratios close to 0 (\%spruce values close to $100 \%$ ). However, the total uncertainty is likely much larger. It should be noted that in addition to MAs, other organic aerosol species, such as syringol and guaiacol, their derivatives, and retene, could also be used to differentiate between hardwood and softwood burning (e.g. Bari et al., 2009).

The error bars in Fig. 8 represent the minimum and the maximum PE observed for the actual analytical method, and thus the range can be considered a measure of the variability. For the levoglucosan to mannosan ratio the variability ranged from 3.5 to $24 \%$.

\section{Conclusions}

In the current study we have compared the results of thirteen different analytical methods used to quantify monosaccharide anhydrides (MAs) (i.e. levoglucosan, mannosan and galactosan) in ambient aerosol filter samples. To our knowledge, this is the first major intercomparison that has been conducted and reported in the scientific literature with respect to these compounds. All major methods used for analysis of MAs in ambient aerosol filter samples, and which have been reported in the scientific literature so far, are represented in the present intercomparison.

It is shown that the accuracy for levoglucosan, presented as the mean percentage error (PE) for each participating laboratory, varied from -63 to $20 \%$; however, for $62 \%$ of the laboratories the mean PE was within $\pm 10 \%$, and for $85 \%$ the mean PE was within $\pm 20 \%$. The variability of the various analytical methods, as defined by their minimum and maximum PE value, ranged from 3.2 to $41 \%$ for levoglucosan. These results show that for levoglucosan the accuracy is only slightly lower than that reported for an analysis of $\mathrm{SO}_{4}^{2-}$ on filter samples, a constituent that has been analysed by numerous laboratories for several decades, typically by ion chromatography, and which should be considered a fairly easy constituent to analyse. Hence, the results obtained for levoglucosan with respect to accuracy are encouraging and suggest that levels of levoglucosan, and to a somewhat lesser 
extent for mannosan and galactosan, obtained by most analytical methods currently used to quantify monosaccharide anhydrides in ambient aerosol filter samples provide comparable results.
Finally, the various analytical methods used in the current study should be tested for other aerosol matrices and concentrations as well, the most obvious being summertime aerosol samples influenced by wildfires and/or agricultural fires. 
Appendix A: Detailed description of analytical methods used for quantification of levoglucosan, mannosan and galactosan in the intercomparison

\section{A1 HPAEC-Ion chromatography (IC)}

\section{A1.1 Lab. 2}

For the analysis, punches of the filters $\left(1 \mathrm{~cm}^{2}\right)$ were spiked with ${ }^{13} \mathrm{C}_{6}$-levoglucosan and extracted with $5 \mathrm{~mL}$ deionised water under $15 \mathrm{~min}$ gentle rotation. $50 \mu \mathrm{L}$ of the filtered extracts (IC Acrodisc ${ }^{\circledR}$ syringe filter $0.45 \mu \mathrm{m}$ Supor $^{\circledR}$ (PES) membrane) were used for analysis. The MAs were measured using ion chromatography (Dionex IC-3000) coupled to a quadrupole mass spectrometer (Dionex MSQ). Separations were made using a Dionex CarboPac ${ }^{\mathrm{TM}}$ PA10 guard column $\left(2 \mathrm{~mm}\right.$ i.d. $\times 50 \mathrm{~mm}$ length) and a Dionex CarboPac ${ }^{\mathrm{TM}}$ PA10 analytical column $(2 \mathrm{~mm}$ i.d. $\times 250 \mathrm{~mm}$ length $)$, a $2 \mathrm{~mm}$ ASRS-300 suppressor, a CR-ATC anion trap column, and a potassium hydroxide eluent generator. Monosaccharide anhydrides were ionized using the ESI technique. The molecular ions of levoglucosan, mannosan and galactosan were monitored at $m / z 161$, whereas that of ${ }^{13} \mathrm{C}_{6}$-levoglucosan was monitored at $m / z 167$, using the selected ion mode. Levoglucosan was used for calibration.

\section{A1.2 Lab. 3}

For the analysis, five punches of the filters with an area of $0.5 \mathrm{~cm}^{2}$ each were extracted together with $5 \mathrm{~mL}$ Milli$\mathrm{Q}$ grade water. Extraction was performed in polypropylene test tubes, which were first agitated with a Vortex and then put into an ultrasonic bath $(20 \mathrm{~min})$. After centrifugation $(10 \mathrm{~min})$ the aqueous extract was transferred into four microcentrifuge vials with $1 \mathrm{~mL}$ solution each. The solutions (injection volume $20 \mu \mathrm{L}$ ) were analysed using ion chromatography with pulsed amperometric detection (HPAEC-PAD, ICS-3000 from Dionex Corp.). The separating column was a CarboPac ${ }^{\mathrm{TM}} \mathrm{MA} 1$, the eluent concentration ranged from $0.48 \mathrm{M} \mathrm{NaOH}$ up to $0.65 \mathrm{M} \mathrm{NaOH}$ with a flow of $0.4 \mathrm{~mL} \mathrm{~min}^{-1}$. Levoglucosan, mannosan and galactosan were identified by their retention time and quantified using external standards.

\section{A1.3 Lab. 7}

For the analysis, punches of the filters $\left(1.6 \mathrm{~cm}^{2}\right)$ were extracted in $0.5 \mathrm{~mL}$ of Milli-Q grade water under ultrasonication for $30 \mathrm{~min}$. The extract was filtered through a syringe filter $(0.45 \mu \mathrm{m})$. The samples were analysed using a Dionex ICS-3000 system. The separation was carried out on a Dionex CarboPac ${ }^{\mathrm{TM}}$ MA1 column $(4 \times 250 \mathrm{~mm})$ with a corresponding guard column $(4 \times 50 \mathrm{~mm})$ at room temperature. The sample injection loop was $25 \mu \mathrm{L}$. The eluent gradient was programmed as follows: $0.52 \mathrm{M} \mathrm{NaOH}$ from 0 to $20 \mathrm{~min}$, 0.52 to $0.65 \mathrm{M} \mathrm{NaOH}$ in $15 \mathrm{~min}$ and held constant for $15 \mathrm{~min}$.
The eluent flow rate was $0.4 \mathrm{~mL} \mathrm{~min}{ }^{-1}$. The waveform used for pulsed amperometric detection was the standard quadruple potential for carbohydrate analysis. Levoglucosan, mannosan and galactosan were identified by their retention time and were quantified using external standards.

\section{A2 HPLC}

\section{A2.1 Lab. 1}

For the analysis, punches $\left(1.5 \mathrm{~cm}^{2}\right)$ of the filter were spiked with ${ }^{13} \mathrm{C}_{6}$-levoglucosan and ${ }^{13} \mathrm{C}_{6}$-galactosan and extracted twice with $2 \mathrm{~mL}$ tetrahydrofuran under ultrasonic agitation (30 min). The filtered extracts (Teflon syringe filter, $0.45 \mu \mathrm{m}$ ) were evaporated to a total volume of $1 \mathrm{~mL}$ in a nitrogen atmosphere. Before analysis the sample solvent elution strength was adapted to the mobile phase by adding Milli-Q water $(0.8 \mathrm{~mL})$. The concentrations of the MAs were determined using high-performance liquid chromatography (HPLC) (Agilent model 1100) in combination with HRTOFMS (high-resolution time-of-flight mass spectrometry, Micromass model LCT) operated in the negative ESI mode. Levoglucosan, mannosan and galactosan were identified on the basis of retention time and mass spectra of authentic standards. Quantification was performed using isotope-labeled standards of levoglucosan and galactosan. The mass traces at $m / z 161.0455$ and 167.0657 were used for quantification (approximately $50 \mathrm{mDa}$ peak width).

\section{A2.2 Lab. 6}

For the analysis, filters were spiked with ${ }^{13} \mathrm{C}_{6}$-levoglucosan and extracted three times with methanol in an ultrasonic bath for $30 \mathrm{~min}$. The three extracts were pooled and evaporated to dryness. The sample was reconstituted with $1 \mathrm{~mL}$ methanol, shaken, and filtered through a nylon filter. The analysis was performed with liquid chromatography-mass spectrometry with ESI in the positive ionisation mode. Sodium acetate $(2 \mathrm{mM})$ was added to the LC mobile phase to form sodium adducts of levoglucosan and mannosan. The analytes were separated by a gradient using $10 \mathrm{mM}$ sodium acetate and methanol as a mobile phase. The LC column was a Benson Polymeric BP-100 Ca++ Carbohydrate Column. Analysis was performed using selected ion monitoring (SIM) of the sodium adducts. The ion monitored for levoglucosan and mannosan was $m / z 185$, for ${ }^{13} \mathrm{C}_{6}$-levoglucosan it was $m / z 191$.

\section{A2.3 Lab. 8}

For the analysis, filter punches $\left(4.5 \mathrm{~cm}^{2}\right)$ were extracted with $2 \mathrm{~mL}$ ultrapure water by $30 \mathrm{~min}$ vortex agitation; $449 \mu \mathrm{L}$ of the filtered extracts (Acrodisc ${ }^{\circledR}$ syringe filters, $0.2 \mu \mathrm{m}$ ) were analysed by liquid chromatography (Dionex DX500) electrospray ionisation - tandem mass spectrometry (Thermo Fisher Scientific LCQ Fleet). Levoglucosan, mannosan and galac- 
tosan were identified and quantified on the basis of retention time and specific multiple reaction monitoring (MRM) transition $(m / z 161-113$ for levoglucosan and galactosan, $m / z 161-101$ for mannosan). External calibrations were performed using standards of levoglucosan, mannosan, and galactosan.

\section{A2.4 Lab. 10}

For the analysis, the entire filter punch was extracted twice with $6 \mathrm{~mL}$ pure water in an ultrasonic bath for $45 \mathrm{~min}$. Extracts were filtered (Teflon syringe filter, $0.2 \mu \mathrm{m}$ ) and $50 \mu \mathrm{L}$ of chloroform was added to prevent bacteria activity. Extracts were kept frozen $\left(-18^{\circ} \mathrm{C}\right)$ until analysis. The analyses were performed using an ultra-performance liquid chromatography (UPLC, Waters) instrument coupled with a triple quadrupole mass spectrometer (Applied Biosystems, model API3200). Separation of MAs was achieved using an Acquity UPLC HSS T3 column, a sample loop of $10 \mu \mathrm{L}$, a mixed water-methanol solvent, and post-column addition of methanol. Levoglucosan, mannosan and galactosan were identified and quantified on the basis of retention time and specific MRM transition $(\mathrm{m} / \mathrm{z}, 161-113$ for levoglucosan and galactosan, $m / z$ 161-113 for mannosan). External calibrations were performed using standards.

\section{A3 GC}

\section{A3.1 Lab. 4}

For the GC-MS analyses, three filter punches $\left(1 \mathrm{~cm}^{2}\right.$ each) were spiked with recovery standard (methyl $O$ L-xylanopyranoside). Each punch was extracted three times with $10 \mathrm{~mL}$ methanol for $5 \mathrm{~min}$ under ultrasonic agitation. The combined extract was reduced in volume with a rotary evaporator to about $1 \mathrm{~mL}$. The filtered concentrate (Teflon syringe filter, $0.45 \mu \mathrm{m}$ ) was completely dried under a stream of nitrogen; $40 \mu \mathrm{L}$ of BSTFA $(N, O$-Bis(trimethylsilyl)trifluoroacetamide) $+1 \%$ chlorotrimethylsilane (TMCS) / pyridine (2/1) was added to the dried sample, and the mixture reacted at $70^{\circ} \mathrm{C}$ for $1 \mathrm{~h}$. An aliquot of $1 \mu \mathrm{L}$ was immediately analysed by GC-MS (Thermo-Finnigan, TRACE GC2000 and Polaris Q). Quantification of the MAs was performed in the scanning mode ( $m / z$ 45-650) from the total ion chromatogram using relative response factors determined by injection of authentic standards of levoglucosan, galactosan, and mannosan.

\section{A3.2 Lab. 5}

For the GC-MS analyses, three to four filter punches $\left(0.79 \mathrm{~cm}^{2}\right.$ each) were spiked with internal standard. Each sample was extracted twice with an $8 \mathrm{~mL}$ dichloromethane / methanol mixture (4/1) for $30 \mathrm{~min}$ in an ultrasonic bath. The filtered extracts (Teflon syringe filter, $0.45 \mu \mathrm{m}$ ) were evaporated to dryness under a gentle flow of nitrogen; $70 \mu \mathrm{L}$ BSTFA and $70 \mu \mathrm{L}$ pyridine were added to derivatise the analytes. The mixtures were reacted at $70^{\circ} \mathrm{C}$ for $3 \mathrm{~h} ; 1 \mu \mathrm{L}$ of the sample was injected into the $\mathrm{GC}$ injector (Agilent $6890 \mathrm{~N}$ ) in the splitless mode. The EI ionisation mass spectrometer with quadrupole mass analyser (Agilent 5973) was operated in the SIM mode, the acquisition frequency was 2.74 cycles s$^{-1}$. The ion at $m / z 333$ was used for the evaluation. Calibration was performed with a standard solution of levoglucosan.

\section{A3.3 Lab. 9}

In the GC-MS method, punches $\left(0.85\right.$ or $\left.1.0 \mathrm{~cm}^{2}\right)$ of the samples were spiked with an internal standard levoglucosan $\left({ }^{2} \mathrm{H}_{7}\right)$ and ultrasonically extracted twice with $5 \mathrm{~mL}$ of a mixture of dichloromethane / methanol (2/1) for 15 min under ultrasonic agitation. The filtered extracts (glass fiber filters, $0.60 \mathrm{~mm}$ ) were concentrated in a rotary evaporator to a small volume (ca. $200 \mu \mathrm{L}$ ), and then to dryness under a nitrogen flow; $50 \mu \mathrm{L}$ BSTFA $+1 \%$ TMCS was added and maintained at $70^{\circ} \mathrm{C}$ for $3 \mathrm{~h}$. After derivatisation, the excess of derivatisation agent was evaporated by a nitrogen flow and hexane was added to obtain a volume of $0.5 \mathrm{~mL}$. The concentrations were determined using PTV-GC (programmable temperature vaporisation gas chromatography) (Thermo-Finnigan, Trace GC) in combination with a MS detector (Thermo-Finnigan, Polaris-Q). A $10 \mu \mathrm{L}$ sample was injected and p-terphenyl was used as a recovery standard. The chromatograms were acquired in the full scan mode $(m / z 50-500)$. Compounds were quantified according to their characteristic ion: levoglucosan $(m / z 204)$, mannosan and galactosan $(m / z 217)$. Quantification was performed using isotope-labeled ${ }^{2} \mathrm{H}_{7}$-levoglucosan $(m / z 220)$.

\section{A3.4 Lab. 11}

For the GC-MS analyses, samples were divided into two parts $\left(2.27 \mathrm{~cm}^{2}\right.$ and rest of the filter). Sedoheptulose was added as an internal standard and filters were extracted by refluxing with $300 \mathrm{~mL}$ dichloromethane / methanol (2/1) for $24 \mathrm{~h}$. The filtered extracts (glass filtration unit, $0.45 \mu \mathrm{m}$ ) were concentrated in a rotary evaporator to a volume of about $2 \mathrm{~mL}$, transferred to a vial and evaporated to dryness under a nitrogen stream. The dried extracts were re-dissolved in pyridine $(100 \mu \mathrm{L})$ and derivatized with $200 \mu \mathrm{L}$ BSTFA $+1 \%$ TMCS at $70^{\circ} \mathrm{C}$ for $3 \mathrm{~h}$. For quantification $1 \mu \mathrm{L}$ of the reaction mixture was injected. The concentrations of MAs were determined by gas chromatography (Agilent 6890) mass spectrometry (Agilent 7873). Levoglucosan was identified on the basis of retention time and mass spectra of an authentic standard. Quantification of the three anhydrosugars was performed in the scanning mode using relative response factors determined by injection of a levoglucosan standard. 


\section{A3.5 Lab. 12} mal desorption gas chromatography time-of-flight mass spectrometry (IDTD-GC-TOFMS). Filter punches (0.12$0.28 \mathrm{~cm}^{2}$ ) were placed into a GC liner, internal standard $\left({ }^{13} \mathrm{C}_{6}\right.$-levoglucosan $)$ was added, and liners were closed. For derivatisation filter punches were soaked with $10 \mu \mathrm{L} N$-Methyl- $N$-(trimethylsilyl)trifluoroacetamide (MSTFA). Closed liners were placed in an oven at $80^{\circ} \mathrm{C}$ for 1h. After this derivatisation step the liners were put into the cold injector. For desorption, the temperature was raised to $300^{\circ} \mathrm{C}$ and kept there for $16 \mathrm{~min}$. During desorption MSTFA was added to the carrier gas. Analytes were focused on a retention gap at $70^{\circ} \mathrm{C}$ followed by GC separation (Agilent 6890). The TOFMS instrument (Leco Pegasus III) was operated at a data acquisition frequency of 25 scans s$^{-1}$. The mass range was $m / z 30-500$. For quantification $m / z 333$ for tris-trimethylsilyl-levoglucosan and $\mathrm{m} / z 338$ for tristrimethylsilyl- ${ }^{13} \mathrm{C}_{6-}$ levoglucosan were used. External calibration was done with native levoglucosan.

\section{A3.6 Lab. 13}

For the GC-MS analyses, filter punches $\left(1 \mathrm{~cm}^{2}\right)$ were extracted three times $(15,10,5 \mathrm{~mL})$ with a mixture of dichloromethane/methanol (3/1) and subjected to ultrasonic agitation $(45,30,15 \mathrm{~min})$. The filtered extracts (Teflon syringe filter, $0.45 \mu \mathrm{m}$ ) were evaporated to dryness in a nitrogen stream. The dry mass was re-dissolved in $1 \mathrm{~mL}$ of dichloromethane; $50 \mu \mathrm{L}$ of each extract solution and $5 \mu \mathrm{L}$ of a 1,4-dithioerythritol solution $\left(0.5 \mu \mathrm{g} \mathrm{mL}^{-1}\right)$ were evaporated to dryness under a stream of nitrogen at $60^{\circ} \mathrm{C} ; 30 \mu \mathrm{L}$ pyridine and $10 \mu \mathrm{L}$ of MSTFA $+1 \%$ TMCS were added, and the mixture was reacted at $80^{\circ} \mathrm{C}$ for $1 \mathrm{~h}$. The solution was evaporated to dryness at $60^{\circ} \mathrm{C}$ under a continuous flow of nitrogen. The dry mass was dissolved in $50 \mu \mathrm{L}$ of dichloromethane containing 1-phenyldodecane $\left(5 \mu \mathrm{g} \mathrm{mL} \mathrm{L}^{-1}\right.$. For quantification $2 \mu \mathrm{L}$ were injected. The concentrations of the anhydrosugars were determined by gas chromatography (Agilent 6890) mass spectrometry (Agilent 5973). Levoglucosan was identified on the basis of retention time and mass spectrum of an authentic standard. Quantification was performed using the selective ion monitoring mode. Compounds were quantified according to their characteristic $m / z 217$ and 204 for levoglucosan and $m / z 246$ for 1-phenyldodecane.

\section{Appendix B: Supplementary tables}

Analyses were carried out using in situ derivatisation ther-

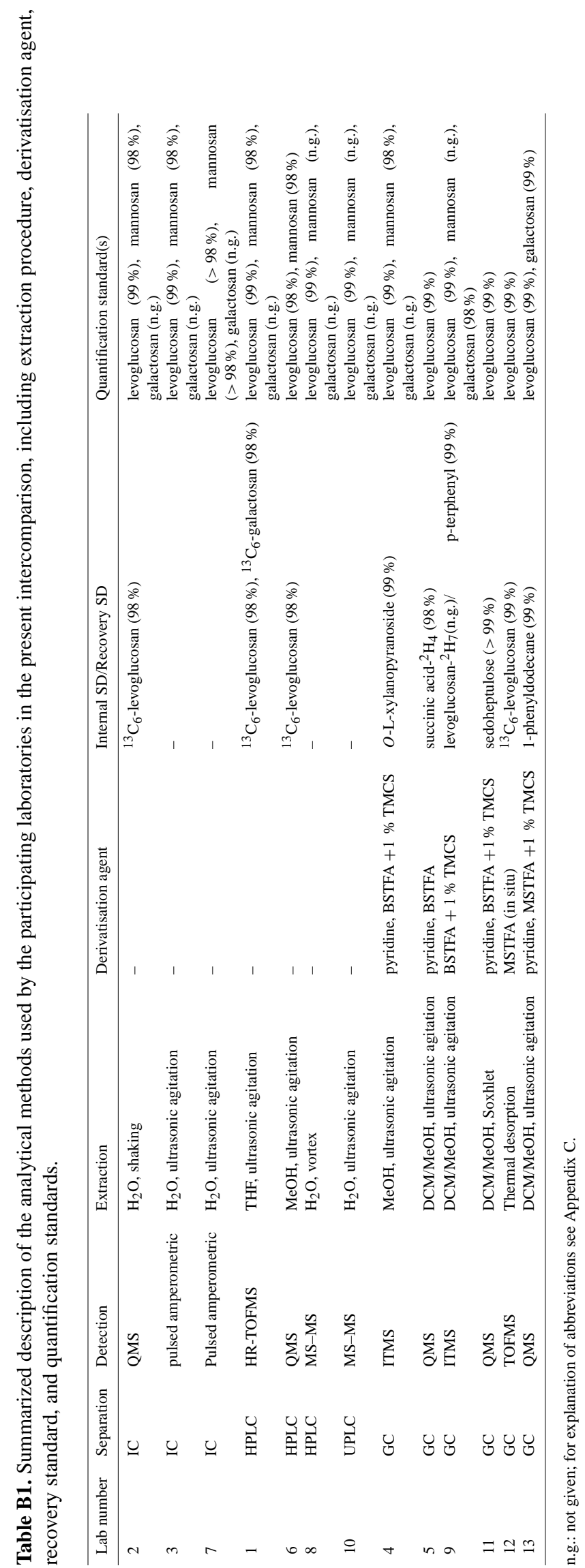


Table B2. Results of the homogeneity test of the six filter samples subjected to the present intercomparison. The results were obtained from one $1.0 \mathrm{~cm} 2$ punch taken from each of the 16 sectors per filter; i.e. a total of 96 analyses were performed for each of the three isomers. The filter samples were analyzed according to the method described in Sect. A2.1.

\begin{tabular}{|c|c|c|c|c|c|c|}
\hline & Filter sample 1 & Filter sample 2 & Filter sample 3 & Filter sample 4 & Filter sample 5 & Filter sample 6 \\
\hline \multicolumn{7}{|l|}{ Levoglucosan } \\
\hline Mean \pm SD $\left(\mathrm{ng} \mathrm{cm}^{-2}\right)$ & $1518 \pm 179$ & $1403 \pm 127$ & $604 \pm 99$ & $440 \pm 48$ & $541 \pm 51$ & $456 \pm 48$ \\
\hline $\operatorname{Median}\left(\mathrm{ng} \mathrm{cm}^{-2}\right)$ & 1478 & 1434 & 631 & 435 & 537 & 445 \\
\hline Mean/Median & 1.03 & 0.98 & 0.96 & 1.01 & 1.01 & 1.03 \\
\hline $\operatorname{RSD}(\%)$ & 12 & 9.1 & 16 & 11 & 9.5 & 10 \\
\hline Outlier & - & - & - & - & - & - \\
\hline \multicolumn{7}{|l|}{ Mannosan } \\
\hline Mean \pm SD $\left(\mathrm{ng} \mathrm{cm}^{-2}\right)$ & $446 \pm 46$ & $370 \pm 46$ & $87 \pm 22$ & $75 \pm 26$ & $103 \pm 20$ & $86 \pm 9$ \\
\hline Median $\left(\mathrm{ng} \mathrm{cm}^{-2}\right)$ & 437 & 366 & 93 & 77 & 109 & 85 \\
\hline Mean/Median & 1.02 & 1.01 & 0.93 & 0.98 & 0.95 & 1.01 \\
\hline $\operatorname{RSD}(\%)$ & 10 & 12 & 26 & 35 & 19 & 10 \\
\hline Outlier & - & - & - & - & 1 & - \\
\hline \multicolumn{7}{|l|}{ Galactosan } \\
\hline Mean $\pm \mathrm{SD}\left(\mathrm{ng} \mathrm{cm}^{-2}\right)$ & $112 \pm 15$ & $98 \pm 11$ & $21 \pm 9.5$ & $19 \pm 7.8$ & $34 \pm 5.2$ & $26 \pm 3.9$ \\
\hline Median $\left(\mathrm{ng} \mathrm{cm}^{-2}\right)$ & 107 & 96 & 21 & 16 & 34 & 26 \\
\hline Mean/Median & 1.04 & 1.02 & 0.99 & 1.13 & 1.00 & 1.02 \\
\hline $\operatorname{RSD}(\%)$ & 13 & 11 & 45 & 42 & 15 & 15 \\
\hline Outlier & & & & 1 & 1 & \\
\hline
\end{tabular}


Table B3. Calculated mean $( \pm \mathrm{SD})$ and median concentrations as well as maximum and minimum concentrations of levoglucosan, mannosan and galactosan in the six filter samples subjected to the intercomparison, as obtained by the various methods applied. Number of values included in the calculated concentrations, outliers and values below the detection limit (BDL) are listed. Outliers and values BDL are not included in the calculated concentrations, nor in the listed maximum and minimum values.

\begin{tabular}{|c|c|c|c|c|c|c|c|c|}
\hline Sample code & Isomer & Mean $\pm \mathrm{SD}\left(\mathrm{ng} \mathrm{cm}^{-2}\right)$ & Median & Max & Min & $n$ & Outliers & BDL \\
\hline \multicolumn{9}{|l|}{ Filter 1} \\
\hline & Levoglucosan & $1730 \pm 302$ & 1765 & 2190 & 965 & 12 & \multicolumn{2}{|l|}{1 (lab. 7) } \\
\hline & Mannosan & $275 \pm 122$ & 300 & 489 & 68 & 9 & \multirow{2}{*}{\multicolumn{2}{|c|}{1 (lab. 9) }} \\
\hline & Galactosan & $76 \pm 40$ & 90 & 124 & 11 & 8 & & \\
\hline \multicolumn{9}{|l|}{ Filter 2} \\
\hline & Levoglucosan & $1592 \pm 317$ & 1631 & 2132 & 873 & 12 & \multicolumn{2}{|l|}{1 (lab. 7) } \\
\hline & Mannosan & $256 \pm 105$ & 263 & 441 & 65 & 9 & \multirow{2}{*}{\multicolumn{2}{|c|}{1 (lab. 9) }} \\
\hline & Galactosan & $68 \pm 34$ & 79 & 101 & 14 & 8 & & \\
\hline \multicolumn{9}{|l|}{ Filter 3} \\
\hline & Levoglucosan & $594 \pm 141$ & 627 & 765 & 280 & 13 & \multirow{3}{*}{1 (lab. 9) } & \multirow[b]{3}{*}{2 (labs. 3 and 8 ) } \\
\hline & Mannosan & $101 \pm 37$ & 99 & 166 & 47 & 9 & & \\
\hline & Galactosan & $39 \pm 18$ & 40 & 68 & 12 & 6 & & \\
\hline \multicolumn{9}{|l|}{ Filter 4} \\
\hline & Levoglucosan & $544 \pm 123$ & 570 & 678 & 268 & 13 & 3 & \multirow[b]{3}{*}{2 (labs. 3 and 8 ) } \\
\hline & Mannosan & $87 \pm 33$ & 80 & 146 & 42 & 9 & \multirow[b]{2}{*}{1 (lab. 9) } & \\
\hline & Galactosan & $37 \pm 20$ & 33 & 71 & 11 & 6 & & \\
\hline \multicolumn{9}{|l|}{ Filter 5} \\
\hline & Levoglucosan & $566 \pm 134$ & 586 & 758 & 258 & 13 & \multirow[b]{3}{*}{1 (lab. 9) } & \multirow[b]{3}{*}{2 (labs. 3 and 8) } \\
\hline & Mannosan & $110 \pm 45$ & 110 & 188 & 45 & 9 & & \\
\hline & Galactosan & $36 \pm 20$ & 35 & 70 & 11 & 6 & & \\
\hline \multicolumn{9}{|l|}{ Filter 6} \\
\hline & Levoglucosan & $521 \pm 122$ & 552 & 670 & 270 & 13 & \multirow[b]{3}{*}{1 (lab. 9) } & \multirow[b]{3}{*}{2 (labs. 3 and 8) } \\
\hline & Mannosan & $99 \pm 36$ & 100 & 162 & 51 & 9 & & \\
\hline & Galactosan & $35 \pm 20$ & 31 & 68 & 9 & 6 & & \\
\hline
\end{tabular}


Table B4. Calculated mean $( \pm \mathrm{SD})$ and median ratios, as well as maximum and minimum ratios of levoglucosan (levo), mannosan (manno) and galactosan (galacto), to the sum of the three isomers ( $\Sigma \mathrm{MAs}$ ) including the mannosan to levoglucosan ratio in the six filter samples subjected to the intercomparison, as obtained by the various methods applied. Number of values included in the calculated values are listed. Outliers and values BDL are not included in the calculated concentrations, nor in the listed maximum and minimum values.

\begin{tabular}{|c|c|c|c|c|c|c|}
\hline Sample code & Isomer & Mean \pm SD & Median & $\operatorname{Max}$ & Min & $n$ \\
\hline \multicolumn{7}{|l|}{ Filter 1} \\
\hline & 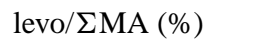 & $82 \pm 2.1$ & 82 & 87 & 81 & 6 \\
\hline & manno/ $\Sigma$ MA $(\%)$ & $14 \pm 1.4$ & 14 & 15 & 11 & 6 \\
\hline & galacto/ $\Sigma \mathrm{MA}(\%)$ & $4.0 \pm 1.7$ & 4.2 & 6.3 & 1.0 & 6 \\
\hline & levo/manno & $5.9 \pm 0.9$ & 5.8 & 7.2 & 4.5 & 8 \\
\hline \multicolumn{7}{|l|}{ Filter 2} \\
\hline & 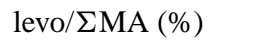 & $82 \pm 1.2$ & 83 & 83 & 80 & 6 \\
\hline & manno/ $\Sigma$ MA $(\%)$ & $14 \pm 1.4$ & 14 & 15 & 12 & 6 \\
\hline & galacto/ $\Sigma \mathrm{MA}(\%)$ & $3.8 \pm 1.4$ & 3.9 & 5.5 & 1.4 & 6 \\
\hline & levo/manno & $5.8 \pm 0.7$ & 5.7 & 7.1 & 4.9 & 8 \\
\hline \multicolumn{7}{|l|}{ Filter 3} \\
\hline & levo/ $/ \mathrm{MA}(\%)$ & $82 \pm 0.7$ & 82 & 83 & 81 & 5 \\
\hline & manno/ $\Sigma$ MA $(\%)$ & $13 \pm 1.2$ & 13 & 14 & 11 & 5 \\
\hline & galacto/ $\Sigma \mathrm{MA}(\%)$ & $4.7 \pm 0.9$ & 5.0 & 5.8 & 3.5 & 5 \\
\hline & levo/manno & $6.0 \pm 1.0$ & 6.0 & 7.5 & 4.5 & 9 \\
\hline \multicolumn{7}{|l|}{ Filter 4} \\
\hline & levo/ $/ \mathrm{MA}(\%)$ & $82 \pm 0.8$ & 82 & 84 & 82 & 5 \\
\hline & manno/ $\Sigma \mathrm{MA}(\%)$ & $13 \pm 1.2$ & 13 & 14 & 11 & 5 \\
\hline & galacto/ $\Sigma \mathrm{MA}(\%)$ & $4.8 \pm 0.9$ & 4.7 & 6.3 & 3.4 & 5 \\
\hline & levo/manno & $6.2 \pm 1.1$ & 6.4 & 7.7 & 4.6 & 9 \\
\hline \multicolumn{7}{|l|}{ Filter 5} \\
\hline & levo/ $\Sigma \mathrm{MA}(\%)$ & $81 \pm 0.8$ & 82 & 82 & 80 & 5 \\
\hline & manno/ $\Sigma$ MA $(\%)$ & $14 \pm 1.5$ & 14 & 16 & 12 & 5 \\
\hline & galacto/ $\Sigma \mathrm{MA}(\%)$ & $4.3 \pm 1.0$ & 4.0 & 6.1 & 3.4 & 5 \\
\hline & levo/manno & $5.3 \pm 1.0$ & 5.7 & 6.9 & 3.6 & 9 \\
\hline \multicolumn{7}{|l|}{ Filter 6} \\
\hline & levo/ $\Sigma$ MA (\%) & $81 \pm 0.6$ & 81 & 82 & 80 & 5 \\
\hline & manno/ $\Sigma$ MA $(\%)$ & $14 \pm 1.5$ & 14 & 16 & 12 & 5 \\
\hline & galacto/ $\Sigma$ MA (\%) & $4.4 \pm 1.5$ & 4.0 & 6.8 & 2.6 & 5 \\
\hline & levo/manno & $5.3 \pm 0.9$ & 5.6 & 6.7 & 3.8 & 9 \\
\hline
\end{tabular}


Appendix C: Abbreviations used

\begin{tabular}{ll}
\hline ACD & Aerosol charge detection \\
BB & Biomass burning \\
BSTFA & $N, O$-Bis(trimethylsilyl)trifluoroacetamide \\
CE & Capillary electrophoresis \\
DCM & Dichloromethane \\
ESI & Electrospray ionisation \\
GC & Gas chromatography \\
HPAEC & High-performance anion-exchange chromatography \\
HPLC & High-performance liquid chromatography \\
HR-TOFMS & High-resolution time-of-flight mass spectrometry \\
ITMS & Ion trap mass spectrometry \\
MAs & Monosaccharide anhydrides \\
MS & Mass spectrometry \\
MS-MS & Tandem mass spectrometry \\
MSTFA & $N$-Methyl- $N$-(trimethylsilyl)trifluoroacetamide \\
MeOH & Methanol \\
PAD & Pulsed amperometric detection \\
PM & Particulate matter \\
QMS & Quadrupole mass spectrometry \\
SO \\
2- & Sulfate \\
THF & Tetrahydrofuran \\
TOFMS & Time-of-flight mass spectrometry \\
TMCS & Chlorotrimethylsilane \\
UPLC & Ultra-performance liquid chromatography \\
&
\end{tabular}


Acknowledgements. The work was supported by the Co-operative Programme for Monitoring and Evaluation of the Long-range Transmission of Air pollutants in Europe (EMEP) under UNECE and the European Union Seventh Framework Programme (FP7/2007-2013) under the ACTRIS project (grant agreement no. 262254).

\section{Edited by: P. Herckes}

\section{References}

Agarwal, S., Aggarwal, S. G., Okuzawa, K., and Kawamura, K.: Size distributions of dicarboxylic acids, ketoacids, $\alpha$ dicarbonyls, sugars, WSOC, OC, EC and inorganic ions in atmospheric particles over Northern Japan: implication for longrange transport of Siberian BB and East Asian polluted aerosols, Atmos. Chem. Phys., 10, 5839-5858, doi:10.5194/acp-10-58392010, 2010.

Alves, C. A., Gonçalves, C., Evtyugina, M., Pio, C. A., Mirante, F., and Puxbaum, H.: Particulate organic compounds emitted from experimental wildland fires in a Mediterranean ecosystem, Atmos. Environ., 44, 2750-2759, 2010.

Bari, M. A., Baumbach, G., Kuch, B., and Scheffknecht, G.: Wood smoke as a source of particle-phase organic compounds in residential areas, Atmos. Environ., 43, 4722-4732, 2009.

Bari, M. A., Baumbach, G., Kuch, B., and Scheffknecht, G.: Temporal variation and impact of wood smoke pollution on a residential area in southern Germany, Atmos. Environ., 44, 3823-3832, 2010.

Blazso, M., Janitsek, S., Gelencsér, A., Artaxo, P., Graham, B., Andreae, M. O.: Study of tropical organic aerosol by thermally assisted alkylation-gas chromatography mass spectrometry, J. Anal. Appl. Pyrol., 68-69, 351-369, 2003.

Booth, A. M., Montague, W. J., Barley, M. H., Topping, D. O., McFiggans, G., Garforth, A., and Percival, C. J.: Solid state and subcooled liquid vapour pressures of cyclic aliphatic dicarboxylic acids, Atmos. Chem. Phys., 11, 655-665, doi:10.5194/acp-11655-2011, 2011.

Caseiro, A. and Oliveira, C.: Variations in wood burning organic marker concentrations in the atmospheres of four European cities, J. Environ. Monitor., 14, 2261-2269, 2012.

Caseiro, A., Marr, I. L., Claeys, M., Kasper-Giebl, A., Puxbaum, H., and Pio, C. A.: Determination of saccharides in atmospheric aerosol using anion-exchange high-performance liquid chromatography and pulsed-amperometric detection, J. Chromatogr. A, 1171, 37-45, 2007.

Caseiro, A., Bauer, H., Schmidl, C., Pio, C. A., and Puxbaum, H.: Wood burning impact on $\mathrm{PM}_{10}$ in three Austrian regions, Atmos. Environ., 43, 2186-2195, 2009.

Claeys, M., Kourtchev, I., Pashynska, V., Vas, G., Vermeylen, R., Wang, W., Cafmeyer, J., Chi, X., Artaxo, P., Andreae, M. O., and Maenhaut, W.: Polar organic marker compounds in atmospheric aerosols during the LBA-SMOCC 2002 biomass burning experiment in Rondônia, Brazil: sources and source processes, time series, diel variations and size distributions, Atmos. Chem. Phys., 10, 9319-9331, doi:10.5194/acp-10-9319-2010, 2010.

Dixon, R. W. and Baltzell, G.: Determination of levoglucosan in atmospheric aerosols using high-performance liquid chromatogra- phy with aerosol charge detection, J. Chromatogr. A, 1109, 214221, 2006.

dos Santos, C. Y. M., Azevedo, D. D., and Neto, F. R. D.: Selected organic compounds from biomass burning found in the atmospheric particulate matter over sugarcane plantation areas, Atmos. Environ., 36, 3009-3019, 2002.

Dye, C. and Yttri, K. E.: Determination of monosaccharide anhydrides in atmospheric aerosols by use of high-performance liquid chromatography combined with high-resolution mass spectrometry, Anal. Chem., 77, 1853-1858, 2005.

Elsasser, M., Crippa, M., Orasche, J., DeCarlo, P. F., Oster, M., Pitz, M., Cyrys, J., Gustafson, T. L., Pettersson, J. B. C., SchnelleKreis, J., Prévôt, A. S. H., and Zimmermann, R.: Organic molecular markers and signature from wood combustion particles in winter ambient aerosols: aerosol mass spectrometer (AMS) and high time-resolved GC-MS measurements in Augsburg, Germany, Atmos. Chem. Phys., 12, 6113-6128, doi:10.5194/acp-126113-2012, 2012.

Elsasser, M., Busch, C., Orasche, J., Schön, C., Hartmann, H., Schnelle-Kreis, J., and Zimmermann, R.: Dynamic changes of the aerosol composition and concentration during different burning phases of wood combustion, Energ. Fuel., 27, 4959-4968, 2013.

Engling, G., Carrico, C. M., Kreidenweis, S. M., Collett, J. L., Day, D. E., Malm, W. C., Lincoln, E., Hao, W. M., Iinuma, Y., and Herrmann, H.: Determination of levoglucosan in biomass combustion aerosol by high-performance anion-exchange chromatography with pulsed amperometric detection, Atmos. Environ., 40, S299-S311, 2006.

Fabbri, D., Chiavari, G., Prati, S., Vassura, I., and Vangelista, M.: Gas chromatography/mass spectrometric characterisation of pyrolysis/silylation products of glucose and cellulose, Rapid Commun. Mass Sp., 16, 2349-2355, 2002.

Fabbri, D., Torri, C., Simoneit, B. R. T., Marynowski, L., Rushdi, A. I., and Fabianska, M. J.: Levoglucosan and other cellulose and lignin markers in emissions from burning of Miocene lignites, Atmos. Environ., 43, 2286-2295, 2009.

Favez, O., El Haddad, I., Piot, C., Boréave, A., Abidi, E., Marchand, N., Jaffrezo, J.-L., Besombes, J.-L., Personnaz, M.-B., Sciare, J., Wortham, H., George, C., and D'Anna, B.: Inter-comparison of source apportionment models for the estimation of wood burning aerosols during wintertime in an Alpine city (Grenoble, France), Atmos. Chem. Phys., 10, 5295-5314, doi:10.5194/acp-10-52952010, 2010.

Fine, P. M., Cass, G. R., and Simoneit, B. R. T.: Chemical characterization of fine particle emissions from fireplace combustion of woods grown in the northeastern United States, Environ. Sci. Technol., 35, 2665-2675, 2001.

Fine, P. M., Cass, G. R., and Simoneit, B. R. T.: Chemical characterization of fine particle emissions from the fireplace combustion of woods grown in the southern United States, Environ. Sci. Technol., 36, 1442-1451, 2002.

Fine, P. M., Cass, G. R., and Simoneit, B. R. T.: Chemical characterization of fine particle emissions from the fireplace combustion of wood types grown in the Midwestern and Western United States, Environ. Eng. Sci., 21, 387-409, 2004.

Fraser, M. P. and Lakshmanan, K.: Using levoglucosan as a molecular marker for the long-range transport of biomass combustion aerosols, Environ. Sci. Technol., 34, 4560-4564, 2000. 
Frey, A. K., Tissari, J., Saarnio, K. M., Timonen, H. J., TolonenKivimaki, O., Aurela, M. A., Saarikoski, S. K., Makkonen, U., Hytonen, K., Jokiniemi, J., Salonen, R. O., and Hillamo, R. E. J.: Chemical composition and mass size distribution of fine particulate matter emitted by a small masonry heater, Boreal Environ. Res., 14, 255-271, 2009.

Gao, S., Hegg, D. A., Hobbs, P. V., Kirchstetter, T. W., Magi, B., I., and Sadilek, M.: Water-soluble organic components in aerosols associated with savanna fires in southern Africa: Identification, evolution, and distribution, J. Geophys. Res.-Atmos., 108, 8491, doi:10.1029/2002JD002324, 2003.

Garcia, C. D., Engling, G., Herckes, P., Collett, J. L., and Henry, C. S.: Determination of levoglucosan from smoke samples using microchip capillary electrophoresis with pulsed amperometric detection, Environ. Sci. Technol., 39, 618-623, 2005.

Gelencsér, A., May, B., Simpson, D., Sanchez-Ochoa, A., KasperGiebl, A., Puxbaum, H., Caseiro, A., Pio, C., and Legrand, M.: Source apportionment of PM2.5 organic aerosol over Europe: Primary/secondary, natural/anthropogenic, and fossil/biogenic origin, J. Geophys. Res.-Atmos., 112, D23S04, doi:10.1029/2006JD008094, 2007.

Gonçalves, C., Alves, C., Evtyugina, M., Mirante, F., Pio, C., Caseiro, A., Schmidl, C., Bauer, H., Carvalho, F.: Characterisation of $\mathrm{PM}_{10}$ emissions from wood stove combustion of common woods grown in Portugal, Atmos. Environ., 44, 4474-4480, 2010.

Gonçalves, C., Alves, C., Fernandes, A. P., Monteiro, C., Tarelho, L., Evtyugina, M., and Pio, C.: Organic compounds in $\mathrm{PM}_{2.5}$ emitted from fireplace and woodstove combustion of typical Portuguese wood species, Atmos. Environ., 45, 4533-4545, 2011.

He, J., Zielinska, B., and Balasubramanian, R.: Composition of semi-volatile organic compounds in the urban atmosphere of Singapore: influence of biomass burning, Atmos. Chem. Phys., 10, 11401-11413, doi:10.5194/acp-10-11401-2010, 2010.

Hennigan, C. J., Sullivan, A. P., Collett, J. L., and Robinson, A. L.: Levoglucosan stability in biomass burning particles exposed to hydroxyl radicals, Geophys. Res. Lett., 37, L09806, doi:10.1029/2010GL043088, 2010.

Herich, H., Gianini, M. F. D., Piot, C., Močnik, G., Jaffrezo, J.-L., Besombes, J.-L., Prévôt, A. S. H., and Hueglin, C.: Overview of the impact of wood burning emissions on carbonaceous aerosols and PM in large parts of the Alpine region. Atmos. Environ., 89, 64-75, 2014.

Hoffmann, D., Tilgner, A., Iinuma, Y., and Herrmann, H.: Atmospheric stability of levoglucosan: A detailed laboratory and modeling study, Environ. Sci. Technol., 44, 694-699, 2010.

Holmes, B. J. and Petrucci, G. A.: Oligomerization of levoglucosan by Fenton chemistry in proxies of biomass burning aerosols, J. Atmos. Chem., 58, 151-166, 2007.

Hornig, J. F., Soderberg, R. H., Barefoot, A. C., and Galasyn, J. F.: Wood smoke analysis: vaporization losses of PAH from filters and levoglucosan as a distinctive marker for wood smoke, in: Polynuclear Aromatic Hydrocarbons: Mechanisms, Methods, and Metabolism, edited by: Cooke, M. and Dennis, A. J., Battelle Press, Columbus, OH, 561-568, 1985.

Hsu, C. L., Cheng, C. Y., Lee, C. T., and Ding, W. H.: Derivatization procedures and determination of levoglucosan and related monosaccharide anhydrides in atmospheric aerosols by gas chromatography-mass spectrometry, Talanta, 72, 199-205, 2007.
Iinuma, Y., Bruggemann, E., Gnauk, T., Muller, K., Andreae, M. O., Helas, G., Parmar, R., and Herrmann, H.: Source characterization of biomass burning particles: The combustion of selected European conifers, African hardwood, savanna grass, and German and Indonesian peat, J. Geophys. Res.-Atmos., 112, D08209, doi:10.1029/2006JD007120, 2007.

Iinuma, Y., Engling, G., Puxbaum, H., and Herrmann, H.: A highly resolved anion-exchange chromatographic method for determination of saccharidic tracers for biomass combustion and primary bio-particles in atmospheric aerosol, Atmos. Environ., 43, 13671371, 2009.

Jordan, T. B. and Seen, A. J.: Effect of airflow setting on the organic composition of woodheater emissions, Environ. Sci. Technol., 39, 3601-3610, 2005.

Kourtchev, I., Hellebust, S., Bell, J. M., O’Connor, I. P., Healy, R. M., Allanic, A., Healy, D., Wenger, J. C., and Sodeau, J. R.: The use of polar organic compounds to estimate the contribution of domestic solid fuel combustion and biogenic sources to ambient levels of organic carbon and PM2.5 in Cork Harbour, Ireland, Sci. Total Environ., 409, 2143-2155, 2011.

Krumal, K., Mikuska, P., Vojtesek, M., and Vecera, Z.: Seasonal variations of monosaccharide anhydrides in $\mathrm{PM}_{1}$ and $\mathrm{PM}_{2.5}$ aerosol in urban areas, Atmos. Environ., 44, 5148-5155, 2010.

Larsen, R. K., Schantz, M. M., and Wise, S. A.: Determination of levoglucosan in particulate matter reference materials, Aerosol Sci. Technol., 40, 781-787, 2006.

Lin, L., Lee, M. L., and Eatough, D. J.: Gas chromatographic analysis of organic marker compounds in fine particulate matter using solid-phase microextraction, J. Air Waste Manage., 57, 53-58, 2007.

Ma, Y., Hays, M. D., Geron, C. D., Walker, J. T., and Gatari Gichuru, M. J.: Technical Note: Fast two-dimensional GC-MS with thermal extraction for anhydro-sugars in fine aerosols, Atmos. Chem. Phys., 10, 4331-4341, doi:10.5194/acp-10-43312010, 2010.

Maenhaut, W., Vermeylen, R., Claeys, M., Vercauteren, J., Matheeussen, C., and Roekens, E.: Assessment of the contribution from wood burning to the $\mathrm{PM}_{10}$ aerosol in Flanders, Belgium, Sci. Total Environ., 437, 226-236, 2012.

May, B., Wagenbach, D., Hammer, S., Steier, P., Puxbaum, H., and Pio, C.: The anthropogenic influence on carbonaceous aerosol in the European background, Tellus B, 61, 464-472, 2009.

Mazzoleni, L. R., Zielinska, B., and Moosmüller, H.: Emissions of levoglucosan, methoxy phenols, and organic acids from prescribed burns, laboratory combustion of wildland fuels, and residential wood combustion, Environ. Sci. Technol., 41, 21152122, 2007.

Medeiros, P. M. and Simoneit, B. R. T.: Analysis of sugars in environmental samples by gas chromatography-mass spectrometry, J. Chromatogr. A, 1141, 271-278, 2007.

Nolte, C. G., Schauer, J. J., Cass, G. R., and Simoneit, B. R. T.: Highly polar organic compounds present in wood smoke and in the ambient atmosphere, Environ. Sci. Technol., 35, 1912-1919, 2001.

Oja, V. and Suuberg, E. M.: Vapor pressures and enthalpies of sublimation of D-glucose, D-xylose, cellobiose, and levoglucosan, J. Chem. Eng. Data, 44, 26-29, 1999.

Oliveira, C., Pio, C., Alves, C., Evtyugina, M., Santos, P., Goncalves, V., Nunes, T., Silvestre, A J. D., Palmgren, F., 
Wahlin, P., and Harrad, S.: Seasonal distribution of polar organic compounds in the urban atmosphere of two large cities from the North and South of Europe, Atmos. Environ., 41, 5555-5570, 2007.

Orasche, J., Schnelle-Kreis, J., Abbaszade, G., and Zimmermann, R.: Technical Note: In-situ derivatization thermal desorption GC-TOFMS for direct analysis of particle-bound non-polar and polar organic species, Atmos. Chem. Phys., 11, 8977-8993, doi:10.5194/acp-11-8977-2011, 2011.

Orasche, J., Seidel, T., Hartmann, H., Schnelle-Kreis, J., Chow, J. C., Ruppert, H., and Zimmermann, R.: Comparison of emissions from wood combustion. Part 1: Emission factors and characteristics from different small-scale residential heating appliances considering particulate matter and polycyclic aromatic hydrocarbon (PAH)-related toxicological potential of particle-bound organic species, Energ. Fuel., 26, 6695-6704, 2012.

Orasche, J., Schnelle-Kreis, J., Schoen, C., Hartmann, H., Ruppert, H., Arteaga-Salas, J. M., and Zimmermann, R.: Comparison of emissions from wood combustion. Part 2: Impact of combustion conditions on emission factors and characteristics of particle-bound organic species and polycyclic aromatic hydrocarbon (PAH)-related toxicological potential, Energ. Fuel., 27, 1482-1491, 2013.

Oros, D. R. and Simoneit, B. R. T.: Identification of molecular tracers in organic aerosols from temperate climate vegetation subjected to biomass burning, Aerosol Sci. Technol., 31, 433-445, 1999.

Pashynska, V., Vermeylen, R., Vas, G., Maenhaut W., and Claeys, M.: Development of a gas chromatographic/ion trap mass spectrometric method for the determination of levoglucosan and saccharidic compounds in atmospheric aerosols. Application to urban aerosols, J. Mass Spectrom., 37, 1249-1257, 2002.

Piazzalunga, A., Fermo, P., Bernardoni, V., Vecchi, R., Valli, G., and De Gregorio, M. A.: A simplified method for levoglucosan quantification in wintertime atmospheric particulate matter by high-performance anion-exchange chromatography coupled with pulsed amperometric detection, Int. J. Environ. Anal. Chem., 90, 934-947, 2010.

Piazzalunga, A., Belis, C., Bernardoni, V., Cazzuli, O., Fermo, P., Valli, G., and Vecchi, R.: Estimates of wood burning contribution to PM by the macro-tracer method using tailored emission factors, Atmos. Environ., 45, 6642-6649, 2011.

Pietrogrande, M. C., Bacco, D., and Rossi, M.: Chemical characterization of polar organic markers in aerosols in a local area around Bologna, Italy, Atmos. Environ., 75, 279-286, 2013.

Piot, C., Jaffrezo, J.-L., Cozic, J., Pissot, N., El Haddad, I., Marchand, N., and Besombes, J.-L.: Quantification of levoglucosan and its isomers by High Performance Liquid Chromatography Electrospray Ionization tandem Mass Spectrometry and its applications to atmospheric and soil samples, Atmos. Meas. Tech., 5, 141-148, doi:10.5194/amt-5-141-2012, 2012.

Puxbaum, H., Caseiro, A., Sanchez-Ochoa, A., Kasper-Giebl, A., Claeys, M., Gelencsér, A., Legrand, M., Preunkert, S., and Pio, C.: Levoglucosan levels at background sites in Europe for assessing the impact of biomass combustion on the European aerosol background, J. Geophys. Res.-Atmos., 112, D23S05, doi:10.1029/2006JD008114, 2007.

Ruehl, C. R., Ham, W. A., and Kleeman, M. J.: Temperatureinduced volatility of molecular markers in ambient air- borne particulate matter, Atmos. Chem. Phys., 11, 67-76, doi:10.5194/acp-11-67-2011, 2011.

Saarnio, K., Aurela, M., Timonen, H., Saarikoski, S., Teinila, K., Makela, T., Sofiev, M., Koskinen, J., Aalto, P. P., Kulmala, M., Kukkonen, J., and Hillamo, R.: Chemical composition of fine particles in fresh smoke plumes from boreal wild-land fires in Europe, Sci. Total Environ., 408, 2527-2542, 2010a.

Saarnio, K., Teinila, K., Aurela, M., Timonen, H., and Hillamo, R.: High-performance anion-exchange chromatography-mass spectrometry method for determination of levoglucosan, mannosan, and galactosan in atmospheric fine particulate matter, Anal. Bioanal. Chem., 398, 2253-2264, 2010 b.

Saffari, A., Daher, N., Samara, C., Voutsa, D., Kouras, A., Manoli, E., Karagkiozidou, O., Vlachokostas, C., Moussiopoulos, N., Shafer, M. M., Schauer, J. J., and Sioutas, C.: Increased biomass burning due to the economic crisis in Greece and its adverse impact on wintertime air quality in Thessaloniki, Environ. Sci. Technol., 47, 13313-13320, 2013.

Schkolnik, G. and Rudich, Y.: Detection and quantification of levoglucosan in atmospheric aerosols: A review, Anal. Bioanal. Chem., 385, 26-33, 2006.

Schkolnik, G., Falkovich, A. H., Rudich, Y., Maenhaut, W., and Artaxo, P.: New analytical method for the determination of levoglucosan, polyhydroxy compounds, and 2-methylerythritol and its application to smoke and rainwater samples, Environ. Sci. Technol., 39, 2744-2752, 2005.

Schmidl, C., Marr, L. L. Caseiro, A., Kotianova, P., Berner, A., Bauer, H., Kasper-Giebl, A., and Puxbaum, H.: Chemical characterisation of fine particle emissions from wood stove combustion of common woods growing in mid-European Alpine regions, Atmos. Environ. 42, 126-141, 2008.

Schnelle-Kreis, J., Kunde, R., Schmoeckel, G., Abbaszade, G., Gaderer, M., Diemer, J., Ott, H., and Zimmermann, R.: Anteil von Partikelemissionen aus Holzverbrennung an PM10Feinstaubimmissionen im städtischen Umfeld am Beispiel von Augsburg - Teil 1: Emissions- und Immissionsmessungen, Gefahrst. Reinhalt. L., 5, 203-209, 2010.

Sillanpää, M., Saarikoski, S., Hillamo, R., Pennanen, A., Makkonen, U., Spolnik, Z., Van Grieken, R., Koskentalo, T. A., and Salonen, R. O.: Chemical composition, mass size distribution and source analysis of long-range transported wildfire smokes in Helsinki, Sci. Total Environ., 350, 119-135, 2005.

Simoneit, B. R. T.: A review of biomarker compounds as source indicators and tracers for air pollution, Environ. Sci. Pollut., 6, 159-169, 1999.

Simoneit, B. R. T., Schauer, J. J., Nolte, C. G., Oros, D. R., Elias, V. O., Fraser, M. P., Rogge, W. F., and Cass, G. R.: Levoglucosan, a tracer for cellulose in biomass burning and atmospheric particles, Atmos. Environ., 33, 173-182, 1999.

Simpson, C. D., Dills, R. L., Katz, B. S., and Kalman, D. A.: Determination of levoglucosan in atmospheric fine particulate matter, J. Air Waste Manage., 54, 689-694, 2004.

Slade, J. H. and Knopf, D. A.: Heterogeneous OH oxidation of biomass burning organic aerosol surrogate compounds: assessment of volatilisation products and the role of $\mathrm{OH}$ concentration on the reactive uptake kinetics, Phys. Chem. Chem. Phys., 15, 5898-5915, 2013.

Sullivan, A. P., Holden, A. S., Patterson, L. A., McMeeking, G. R., Kreidenweis, S. M., Malm, W. C., Hao, W. M., Wold, C. E., 
and Collett Jr., J. L.: A method for smoke marker measurements and its potential application for determining the contribution of biomass burning from wildfires and prescribed fires to ambient PM2.5 organic carbon, J. Geophys. Res.-Atmos., 113, D22302, doi:10.1029/2008JD010216, 2008

Szidat, S., Ruff, M., Perron, N., Wacker, L., Synal, H.-A., Hallquist, M., Shannigrahi, A. S., Yttri, K. E., Dye, C., and Simpson, D.: Fossil and non-fossil sources of organic carbon (OC) and elemental carbon (EC) in Göteborg, Sweden, Atmos. Chem. Phys., 9, 1521-1535, doi:10.5194/acp-9-1521-2009, 2009.

Teraji, T. and Arakaki, T.: Bimolecular rate constants between levoglucosan and hydroxyl radical: Effects of $\mathrm{pH}$ and temperature, Chem. Lett., 39, 900-901, 2010.

Timonen, H., Saarikoski, S., Tolonen-Kivimäki, O., Aurela, M., Saarnio, K., Petäjä, T., Aalto, P. P., Kulmala, M., Pakkanen, T., and Hillamo, R.: Size distributions, sources and source areas of water-soluble organic carbon in urban background air, Atmos. Chem. Phys., 8, 5635-5647, doi:10.5194/acp-8-5635-2008, 2008.

van Drooge, B. L. and Ballesta, P. P.: Seasonal and daily source apportionment of polycyclic aromatic hydrocarbon concentrations in PM10 in a semirural European area, Environ. Sci. Technol., 43, 7310-7316, 2009

Vicente, A., Alves, C., Monteiro, C., Nunes, T., Mirante, F., Cerqueira, M., Calvo, A., Pio, C.: Organic speciation of aerosols from wildfires in central Portugal during summer 2009, Atmos. Environ., 57, 186-196, 2012.

Wan, E. C. H. and Yu, J. Z.: Analysis of sugars and sugar polyols in atmospheric aerosols by chloride attachment in liquid chromatography/negative ion electrospray mass spectrometry, Environ. Sci. Technol., 41, 2459-2466, 2007.
Wang, G., Chen, C., Li, J., Zhou, B., Xie, M., Hu, S., Kawamura, K., and Chen,Y.: Molecular composition and size distribution of sugars, sugar-alcohols and carboxylic acids in airborne particles during a severe urban haze event caused by wheat straw burning, Atmos. Environ., 45, 2473-2479, doi:10.1016/j.atmosenv.2011.02.045, 2011.

Weimer, S., Alfarra, M. R., Schreiber, D., Mohr, M., Prévôt, A. S. H., and Baltensperger, U.: Organic aerosol mass spectral signatures from wood-burning emissions: Influence of burning conditions and wood type, J. Geophys. Res.-Atmos., 113, D10304, doi:10.1029/2007JD009309, 2008.

Yttri, K. E., Dye, C., Slørdal, L. H., and Braathen, O. A.: Quantification of monosaccharide anhydrides by liquid chromatography combined with mass spectrometry: Application to aerosol samples from an urban and a suburban site influenced by small-scale wood burning, J. Air Waste Manage., 55, 1169-1177, 2005.

Yttri, K. E., Dye, C., Braathen, O.-A., Simpson, D., and Steinnes, E.: Carbonaceous aerosols in Norwegian urban areas, Atmos. Chem. Phys., 9, 2007-2020, doi:10.5194/acp-9-2007-2009, 2009.

Yttri, K. E., Lund Myhre, C., Eckhardt, S., Fiebig, M., Dye, C., Hirdman, D., Ström, J., Klimont, Z., and Stohl, A.: Quantifying black carbon from biomass burning by means of levoglucosan - a one-year time series at the Arctic observatory Zeppelin, Atmos. Chem. Phys., 14, 6427-6442, doi:10.5194/acp-14-64272014, 2014. 